\title{
Synergy of stereo cloud top height and ORAC optimal estimation cloud retrieval: evaluation and application to AATSR
}

\author{
Daniel Fisher $^{1, a}$, Caroline A. Poulsen ${ }^{2}$, Gareth E. Thomas ${ }^{2}$, and Jan-Peter Muller ${ }^{1}$ \\ ${ }^{1}$ Imaging Group, Mullard Space Science Laboratory, University College London, Holmbury St. Mary, \\ Dorking, Surrey, RH5 6NT, England, UK \\ ${ }^{2}$ Rutherford Appleton Laboratory, Didcot, Oxfordshire, UK \\ anow at: Earth and Environmental Dynamics Research Group, Department of Geography, \\ King's College London, The Strand, London, WC2R 2LS, UK \\ Correspondence to: Daniel Fisher (daniel.fisher@kcl.ac.uk)
}

Received: 25 March 2015 - Published in Atmos. Meas. Tech. Discuss.: 27 May 2015

Revised: 23 February 2016 - Accepted: 24 February 2016 - Published: 7 March 2016

\begin{abstract}
In this paper we evaluate the impact on the cloud parameter retrievals of the ORAC (Optimal Retrieval of Aerosol and Cloud) algorithm following the inclusion of stereo-derived cloud top heights as a priori information. This is performed in a mathematically rigorous way using the ORAC optimal estimation retrieval framework, which includes the facility to use such independent a priori information. Key to the use of a priori information is a characterisation of their associated uncertainty.

This paper demonstrates the improvements that are possible using this approach and also considers their impact on the microphysical cloud parameters retrieved. The Along-Track Scanning Radiometer (AATSR) instrument has two views and three thermal channels, so it is well placed to demonstrate the synergy of the two techniques. The stereo retrieval is able to improve the accuracy of the retrieved cloud top height when compared to collocated Cloud-Aerosol Lidar and Infrared Pathfinder Satellite Observations (CALIPSO), particularly in the presence of boundary layer inversions and high clouds. The impact of the stereo a priori information on the microphysical cloud properties of cloud optical thickness (COT) and effective radius (RE) was evaluated and generally found to be very small for single-layer clouds conditions over open water (mean RE differences of $2.2( \pm 5.9)$ microns and mean COD differences of $0.5( \pm 1.8)$ for single-layer ice clouds over open water at elevations of above $9 \mathrm{~km}$, which are most strongly affected by the inclusion of the a priori).
\end{abstract}

\section{Introduction}

Clouds play a key role in the Earth's climate system and have long been recognised as important moderators of the atmosphere, strongly modulating both incoming shortwave (SW) and outgoing longwave (LW) radiation. At short wavelengths, due to the global fractional cloud occurrence being on the order of 0.6 to 0.7 (Stubenrauch et al., 2013), they lead to an approximate doubling of the Earth's average albedo from 0.15 to 0.3 (Cess, 1976) and impart a strong cooling effect. At long wavelengths, clouds absorb and re-emit outgoing LW radiation leading to a warming effect, especially at high altitudes. The magnitudes of the conflicting radiative components are, in turn, dependent on a number of microphysical (cloud optical depth, particle size) and macrophysical (fraction, altitude) cloud parameters. Observational analyses demonstrate that when the components are combined, the current overall radiative effect of clouds is one of SW cooling (Ramanathan et al., 1989; Ardanuy et al., 1991; Kiehl et al., 1994; Wielicki et al., 1996; Kiehl and Trenberth, 1997; Allan, 2011), but there is significant spatial heterogeneity. Due to the conflicting radiative effects and strong spatial variability, effective incorporation of cloud radiative behaviour into climate models is tremendously challenging and is one of the main causes of uncertainty in projecting the future state of the climate (Wetherald and Manabe, 1988; Cess et al., 1989, 1990, 1996; Colman, 2003; Soden and Held, 2006; Webb et al., 2006; Soden et al., 2008; Andrews et al., 2012; Zelinka et al., 2013; Sherwood et al., 2014). Reduc- 
ing this uncertainty has been identified by the Intergovernmental Panel on Climate Change (IPCC, Stocker et al., 2013) as a key requirement for improving consensus between climate projections and therefore, gaining a better understanding of the future state of the climate. In order to reduce the uncertainties related to cloud more detailed and informative tests of the cloud parameterisation schemes employed in a climate models are required (Stephens, 2005). Such analysis can be achieved through assessing a model's ability to replicate cloudy conditions of the present day, which necessitates the use of observational data. In particular, observational data that is accurate, consistent, long-term, well characterised, and global in scope. The target requirements of these data are typically in the following ranges: spatial resolution of $\sim 50 \mathrm{~km}$, temporal resolution of $\sim 3 \mathrm{~h}$, cloud amount accuracy of between 0.01 and 0.05 , cloud pressure accuracy of 15 and $50 \mathrm{hPa}$, cloud temperature accuracy of between 1 and $5 \mathrm{~K}$, cloud water path accuracy of $25 \%$, and cloud effective radius accuracy of between 5 and $10 \%$ (Ohring et al., 2005).

Satellite-borne instruments can well fulfil these requirements, and there are now numerous observational methods capable of retrieving both macro- and microphysical cloud properties. An excellent assessment of the most prominent algorithms and sensors is provided in Stubenrauch et al. (2013). Most retrieval algorithms tend to rely on absolute radiometric measurements, with cloud microphysical observations being derived from channels in the visible and nearinfrared (Nakajima et al., 1990) and cloud macrophysical observations being derived separately from infrared measurements using brightness temperatures, and algorithms such as the IR-split window method (Rossow and Garder, 1993) or $\mathrm{CO}_{2}$ slicing (Menzel et al., 1983).

The ORAC (Optimal Retrieval of Aerosol and Cloud) algorithm (Poulsen et al., 2012; Watts et al., 1998) employs the optimal estimation approach (Rogers, 2000) based on radiometric retrieval principles and has been extensively applied to the Along Track Scanning Radiometer Instruments (ATSR), specifically ATSR-2 (1995-2008, Mutlow et al., 1999) and the Advanced-ATSR (2002-2012, LlewellynJones et al., 2001, AATSR). The radiometric configuration of ATSR-2 and AATSR comprises seven channels at 0.55, $0.67,0.87,1.6,3.7,11$ and $12 \mu \mathrm{m}$ and enables the ORAC optimal estimation algorithm to effectively retrieve both macroand micro-physical cloud properties. Uniquely, in order to ensure LW and SW radiative consistency, the algorithm fits a physically consistent model of cloud to observations spanning shortwave and thermal channels, the visible to the infrared, extracting information on the height, optical depth, and particle size, whilst rigorously treating model and observation errors. This approach provides detailed estimation of the uncertainty in the retrieved quantities, and a quantification of the "goodness of fit" of the observations to the cloud forward model.

All radiometric approaches, irrespective of the algorithm employed, are known to suffer from poor performance in a number of common cloud conditions (Baum and Wielicki 1994; Rossow et al., 2005; Garay et al., 2008; Menzel et al., 2008; Marchand et al., 2010). For example, Sayer et al. (2011) provides important caveats to the use of ORAC cloud optical depth retrievals in multi-layer cloud systems, and for cloud effective radius in the case of ice clouds. A pertinent assessment of the problematic cloud conditions for macrophysical retrievals using radiometric methods is presented in Marchand et al. (2010). In particular, boundary layer stratocumulus clouds, trade cumulus/broken clouds, high, thin clouds such as cirrus, and multilayer cloud systems are identified as being very challenging for the radiometric approaches, with substantial biases in the retrieved CTH (cloud top height). The Marchand et al. (2010, loc. cit.) study demonstrates the potential for the application of the geometric approach afforded by stereo capable instruments in this instance the Multi-angle Imaging SpectroRadiometer (Moroney et al., 2002; Muller et al., 2002, 2007, 2013) - for the effective determination of macrophysical cloud parameters in cloud conditions which are challenging for radiometric approaches.

The ATSR instrument makes use of a dual-view conical scanning set up, with an initial observation in the forward direction along the satellite track at a $55^{\circ}$ viewing zenith angle (decreasing to $47^{\circ}$ viewing zenith angle at the edges of the forward scan) and a second observation at nadir with a viewing zenith angle of $2^{\circ}$ (increasing to $22^{\circ}$ viewing zenith angle at the edges of the nadir scan). The instrument resolution at the sub-satellite point is $1 \mathrm{~km}^{2}$. The ATSR series of instruments has a long time series, IR channels from 1991 and visible/IR channels until 2012, and will be followed on by SLSTR (Sea and land surface Temperature Radiometer) in the near future. The instrument's detectors are low noise and well calibrated (the calibration blackbodies employed are accurate to $20 \mathrm{mK}$, Smith et al., 2012) with onboard visible and IR calibration systems, making it ideal to study cloud trends. The arrangement of the ATSR instrument facilitates the application of stereo-photogrammetric techniques for the determination of macrophysical cloud properties. In turn, this allows for the synergistic application of both geometric and radiometric macrophysical cloud parameter retrieval from a single instrument. Many groups are now using optimal estimation techniques to estimate cloud properties (e.g. Heidinger et al., 2010; Watts et al., 1998); however the capability of optimal estimation to include a priori information is not always utilised due to a lack of collocated information of sufficient accuracy and independence. Heidinger et al. (2010) have used climatological data as a priori information with mixed results, OCA (optimal cloud analysis) and ORAC use European Centre for Medium-range Weather Forecasting (ECMWF) ERA Interim reanalysis sea surface temperature data as a priori to the surface temperature state vector. High-resolution Spinning Enhanced Visible and InfraRed Imager (SEVIRI) visible imagery can be used to provide a priori cloud fraction. A priori cloud top height data 
is difficult to identify because of the high temporal variability of the cloud parameters. This work reports on the first instance of independent, collocated CTH data being used to achieve more accurate $\mathrm{CTH}$ retrievals. This synergistic application of a geometric and radiometric approach is evaluated in terms of macro- and microphysical impacts, using the AATSR instrument in combination with the ORAC retrieval and the census stereo algorithm (Zabih and Woodfill, 1994).

The next section introduces the ORAC cloud retrieval algorithm. This is followed in Sect. 3 by a description of the stereo algorithm. In Sect. 4 the method for the synergistic application of the radiometric and geometric approaches, in this instance the application of the stereo-derived CTH as an a priori into the ORAC retrieval, is given. The effect of the inclusion of a priori data on the performance of the ORAC retrieval in terms of cloud macrophysics is then considered through an inter-comparison against lidar-derived cloud top layer (CTL) elevations from the Cloud-Aerosol Lidar with Orthogonal Polarization (CALIOP) instrument. For cloud microphysics a self-comparison between the ORAC retrieval with and without a priori data is undertaken. In Sect. 6 a discussion of the outcomes of Sect. 5 is presented. Finally conclusions are drawn in Sect. 7.

\section{Optimal estimation cloud retrieval algorithm}

The ORAC algorithm (Poulsen et al., 2012, Watts et al., 1998) is an optimal estimation retrieval that can be used to determine both aerosol and cloud properties from visible/infrared satellite radiometers. In the case of cloud retrievals the algorithm fits radiances computed from LUTs (look-up tables) created from DIScrete Ordinates Radiative Transfer (DISORT) (Stamnes et al., 1988) to the TOA (top of atmosphere) signal measured by the satellite by varying the cloud optical depth, effective radius cloud top pressure, phase and surface temperature simultaneously. The result of retrieving all parameters by varying all channels simultaneously is a radiatively consistent set of cloud properties. The cloud retrieval has thus far been applied to ATSR-2 and AATSR, as well as SEVIRI, Advanced Very High Resolution Radiometer (AVHRR) and MODerate Resolution Imaging Spectroradiometer (MODIS) in the context of the ESA Climate Change Initiative (CCI) programme (Stengel et al., 2013).

The optimal estimation (OE) framework of ORAC provides several key advantages.

- The ability to include prior knowledge of the retrieved quantities is built into the method. In previous OE cloud retrievals the only constraint has been on the retrieval of surface temperature and is provided by the ERA Interim reanalysis.

- The retrieval provides comprehensive uncertainty propagation, allowing measurement uncertainty, forward model uncertainty (due to approximations and assumptions which must be made in the modelling to TOA radiance) and uncertainties in a priori knowledge to be combined to give a rigorous estimate of the uncertainty on retrieved values on a pixel by pixel basis.

- SW/LW radiative effects of cloud can be readily computed from the fitted cloud model and is ensured to be consistent with the observed radiances.

Algorithm description

- ORAC uses "on the fly" radiative transfer; the method fits the measurements to the predicted values whilst minimising errors so that they do not exceed predefined limits. Since exact methods are far too slow, the strategy adopted then is to utilise "fast", non-exact, radiative transfer models with analytical gradients. This is achieved by decoupling the cloud and "cloud free atmosphere" parts of the system. The former component is stored in precalculated multiple scattering cloud radiative properties LUTs, while clear atmosphere radiance and transmission calculations are performed on-line using the RTTOV (Radiative Transfer for TIROS Operational Vehicle Sounder) radiative transfer code for both the visible and infrared channels.

- ORAC requires knowledge of the surface reflectance for each visible/near-infrared channel, which is provided by MODIS surface BRDF products (MCD43B) over land and a sea surface reflectance model over the ocean (Sayer et al., 2010). The surface temperature is a retrieved parameter, with the emissivity at each thermal channel determined using the University of WisconsinMadison Baseline Fit Emissivity Database (Seemann et al., 2008).

- The cloud and clear-atmosphere radiative properties and surface properties are merged into a three-layer (below cloud, cloud and above cloud) system by relatively straightforward and computationally efficient equations.

- ORAC uses MIE scattering for water droplets and optical properties from Baran et al. (2005) for ice crystals.

- The ORAC algorithm currently assumes a single cloud layer and retrieves cloud optical depth, cloud top pressure, cloud effective radius, cloud fraction and sea surface temperature, associated uncertainty and goodness fit metric. From these retrieved products liquid and ice water paths can then be calculated.

ORAC code is an open source community code currently being applied to AATSR, AVHRR and MODIS to create longterm climate records of cloud properties, and is available for download from http://proj.badc.rl.ac.uk/orac. 


\section{Stereo-photogrammetric cloud top height determination}

\subsection{Stereo technique}

The stereo-photogrammetric approach relies on the principle of parallax: the distance (or height) dependent displacement of a stationary object when observed from two or more different viewing angles or positions. The only ancillary data requirement is an accurate knowledge of the geometry of the instrument, which enables stereo reconstruction, the conversion of the displacements in the imagery (disparities) into real world observations. In comparison to radiometric cloud retrievals a number of distinct advantages are inherent.

- Stereo retrievals are dependent on the geometry of the imaging system, not the radiometric fidelity. Therefore, they are calibration independent.

- Stereo retrieved heights tend to be associated with the feature with the strongest image contrast. Therefore in the case of multi-layer clouds the cloud height retrieved will be that of the cloud layer that dominates the image signal (Marchand et al., 2010). This is in contrast to an intermediate height that is typically retrieved by radiometric methods in the presence of multi-layer cloud systems.

- Stereo retrievals require very little ancillary data to retrieve CTH. In the case of ATSR, knowledge of the geometry of the instrument is the sole requirement. This significantly reduces the number of sources of uncertainty in the product.

It is also appropriate to mention the key disadvantages of the stereo approach.

- Stereo algorithms, particularly those that employ a window-based approach, tend to smooth over disparity discontinuities (changing from features at different disparities, e.g. from a cloud feature to a land feature). At discontinuities the accuracy of stereo matching algorithms tends to be poor (Scharstein and Szeliski, 2002). The amount of smoothing is dependent on the window size: larger window sizes lead to increased smoothing errors and reduced matching errors (noise); smaller window size lead to reduced smoothing errors and increased matching errors. Selection of a suitable window size is trade-off between these two error sources.

- Changes in the position of cloud features in the alongtrack direction due to wind induced displacement between image acquisitions will cause error in the retrieved stereo height. However, for typical wind speeds the error introduced into the ATSR retrieved heights are comparable to those introduced by the camera model
(Denis et al., 2007; Muller et al., 2007) so wind effects are ignored in the analyses undertaken in this paper. Wind can also cause changes in cloud structure between the image acquisitions, leading to a collocated cloud feature having a slightly different appearance in each image.

- Any global shifts between the images caused by registration errors will lead to biases in the retrieved stereo heights.

The ATSR instruments stereo-photogrammetric capabilities have been exploited variously (Lorenz, 1985; Shin and Pollard, 1999; Prata and Turner, 1997; Muller et al., 2007; Seiz, 2003; Fisher et al., 2014). In terms of application to $\mathrm{CTH}$ retrieval, the most recent study is that by Muller et al. (2007) and involved the development of the M4 stereo image matching algorithm, which was influenced by the development of similar stereo algorithms applied to the MISR instrument (Muller et al., 2002). Here, based on work undertaken by Hirschmuller and Scharstein (2009), we apply the non-parametric census stereo algorithm (Zabih and Woodfill, 1994) to derive CTH. This approach has been demonstrated to be the most effective area-based stereo matcher for imagery with simulated radiometric distortions similar to those found in EO-derived data (Hirschmuller and Scharstein, 2009). As such, the census algorithm is applied in all cases in this study and is described in the following section.

\subsection{Non-parametric stereo matching algorithm}

The pre-processing stage of the census stereo algorithm (Zabih and Woodfill, 1994) is to replace each image pixel with a vector that encodes the structure of the pixels surrounding the pixel being processed, which are referred to as the local neighbourhood and the pixel of interest, respectively. The vector is comprised of zeros and ones (a bit vector) and has the same number of elements as the local neighbourhood. A bit is set to one in this vector if its corresponding pixel in the local neighbourhood is of a lesser intensity (in this case brightness temperature) than the pixel of interest. The use of a bit vector effectively limits the influence of statistically outlying pixels on the pixel of interest during correction for radiometric dissimilarity. It is also unaffected by all radiometric distortions as long as they do not alter the pixel ordering. For any pixel $x$ we can define the census transformation as

$\boldsymbol{\Gamma}(x)=\otimes f(x, n)$,

where $\otimes$ is a concatenation operator that concatenates the results of the comparison function, $f$, to the bit vector, $\boldsymbol{\Gamma}$. The comparison function takes as arguments $x$, the pixel of interest on which a window $\mathbf{N}$ is centred, and $\mathrm{n}$, a pixel from the set that comprises the comparison window, i.e. $n \in \mathbf{N}$. The 
comparison function evaluates to 1 if $n<x$ and 0 if $n \geq x$. The bit vector and the comparison window have the same size. Here, $\mathbf{N}$ is of size 7 by 7 pixels ( $\boldsymbol{\Gamma}$ of length 49 ) as this was found to provide suitable discriminative power for effective stereo matching whilst not increasing computational cost significantly.

Applying Eq. (1) to every pixel in both the reference and comparison images yields two 3-D arrays of bits vectors. In order to locate the correspondences the Hamming distance metric is used to compare the bit vectors as follows,

$S\left(x_{i, j}, u_{r}, v_{r}\right)=\sum \Gamma_{i, j}^{\mathrm{R}} \vee \Gamma_{i+u_{r}, j+v_{r}}^{\mathrm{C}}$,

where the cost $S$ for a given pixel $x$ at the reference image location $i, j$ is determined for $r$ different across and along track displacements, $u$ and $v$. This is achieved by summing the $e x$ clusive or comparisons, as determined by the exclusive or operator $\vee$, between the reference bit vector, $\Gamma^{\mathrm{R}}$, at location $i, j$ and comparison image bit vector, $\Gamma^{\mathrm{C}}$, at the displaced location $i+u_{r} j+v_{r}$. The costs for all disparity assessments are aggregated by a 7 pixel radius median filter to reduce noise. Following cost aggregation a simple spline interpolation routine is employed to estimate sub-pixel disparities in the along-track direction from the along-track disparities associated with the five smallest costs. Across track disparities are returned at integer level accuracy.

\subsection{Post-processing}

The disparities returned by the census algorithm are defined within the imaging coordinate system, and as such, are not physically representative of the measure of CTH. To convert from disparity to $\mathrm{CTH}$, a camera model, which replicates the ATSR imaging geometry, is employed to assign each disparity estimate to an above ellipsoid elevation estimate (Denis et al., 2007). Prior to conversion to elevations, the disparities are first corrected using the AATSR co-registration correction coefficients defined in Fisher and Muller (2013). The accuracy of the elevation estimates from the Census transform varies by channel. For the 11 micron channel, employed in all cases in this study, inter-comparison studies against elevations from the GMTED2010 DEM (Danielson and Gesch, 2011) and CTH observations from CALIOP (Winker et al., 2009) return RMSE statistics of approximately 500 and $1200 \mathrm{~m}$, respectively.

In order to differentiate between the surface and CTH observations the GMTED2010 DEM is used. Any pixel with an elevation that is more than $500 \mathrm{~m}$ above the collocated surface elevation is flagged as a cloud feature with an associated CTH.

A further check is performed on a cloudy pixel to determine if it is located over a surface covered in snow and/or ice, as the census algorithm (and most other stereo matching algorithms) tends to be confused by the textureless/homogenous nature typical of such surface types, leading to erroneous $\mathrm{CTH}$ retrievals. Each orbit is therefore screened for snow/ice pixels using the clear snow/ice mask developed by Istomina et al. (2010) and any flagged pixel is set to a null value. The last step in the post processing is to set all edge pixels to a null value, to remove stereo processor edge artifacts.

\section{Stereo as a priori}

In the current implementation of ORAC for the climate change initiative $(\mathrm{CCI})$ programme the first guess and a priori CTHs are set using the temperature of the $10.8 \mu \mathrm{m}$ channel and an ECMWF temperature profile. As the $10.8 \mu \mathrm{m}$ channel and ECMWF temperature profile are used by ORAC itself in determining $\mathrm{CTH}$, this cannot be considered a prior constraint; thus the a priori is given essentially infinite $\left(10^{8}\right)$ uncertainty, which results in a flat probability function and no prior constraint. In this configuration, the value determined from the temperature is essentially providing a first guess value only.

The setting of the a priori uncertainty is important: too tight and the retrieval will converge to the a priori and ignore the information in the measurements; too loose and the value of the prior information is lost. One example of the use of prior constraint in CTH retrievals is the use of CALIPSO climatological data in the AVHRR Pathfinder Atmospheres Extended (PATMOS-X) product (Heidinger et al., 2010). Using climatological a priori (not collocated in time or space) maybe a technically sound approach to achieve more accurate height retrievals, particularly in the case of thin cirrus; however this is not appropriate when constructing a new, longer-term climatology. In this case the retrievals will converge toward the climatological values reducing the independence and hence reliability of the resulting time series, particularly in detecting long-term changes in CTH.

The optimal estimation algorithmic framework encourages the incorporation of independent a priori information, such as stereo-derived $\mathrm{CTH}$, but it is critical that the a priori data employed be truly independent information. Here, the assumption made is that despite being derived from the same instrument, the fundamental algorithmic differences between the radiometric ORAC and geometric census stereo approaches impart observational independence on the derived CTHs.

The assumption is justified for the following reasons.

- The stereo retrievals are insignificantly affected by systematic noise e.g. those introduced by calibration errors.

- The random error contained within a central pixel, and the average random error of the local neighbourhood of that central pixel will be uncorrelated. Therefore the random errors in the ORAC retrieval, which is pixel based, and the stereo retrieval, which is area based, will also be uncorrelated. Furthermore, ATSR has specifically been designed to have very low noise in the IR 
channels in order to retrieve sea surface temperature at high accuracy (i.e. less than $20 \mathrm{mK}$ (Smith et al., 2012). Although this noise value is for the onboard blackbodies used for sensor calibration, and may be greater for the observations, particularly in the case of colder scenes).

- The main causes of error in the stereo matching are from temporal changes between the views (i.e. changes in the cloud structure between acquisitions) and geometric effects (i.e. projective distortions caused by differing viewing angles), neither of which correlate directly with the measurement error.

The a priori uncertainties for the stereo CTH data are determined through an inter-comparison against the CALIOP lidar using the data set employed in Sect. 5 using the following method:

- The AATSR stereo CTH are quantised into $1 \mathrm{~km}$ bins.

- For each bin the constituent AATSR CTHs are differenced from their collocated CALIOP CTL elevations.

- The uncertainty at each bin is defined as the standard deviation of these height differences.

- During the ORAC processing, each a priori CTH is assigned the uncertainty (standard deviation) from its nearest height bin.

It should be noted that these uncertainties and their method of derivation is likely inappropriate for operational purposes and a more comprehensive analysis of appropriate uncertainty assignment would be required (taking into account, for example, regional wind speed characteristics, optical depth characteristics of typical cloud types at the retrieved elevation, proximity to a feature discontinuity, viewing angle effect of cloud feature distortion; etc.). However, for the initial evaluations undertaken in this paper, the simplistic approach we have employed here is assumed sufficient for the analyses undertaken. The following section aims to assess where the incorporation of the census stereo CTH observations enhances the performance of ORAC and where they lead to degradation.

\section{Inter-comparison of ORAC+stereo with CALIOP observations}

Two differing assessments are made in this section to evaluate the effect of including stereo a priori data in the ORAC retrieval: one focusing on the changes in the retrieved macrophysical characteristics; the other focusing on the retrieved cloud microphysics.

The only macrophysical parameter assessed is the CTH, as the other macrophysical parameter retrieved by ORAC cloud fraction - is not impacted. The census stereo data is not used as a cloud mask; it can only provide an a priori
CTH estimate when the ORAC cloud masking procedure detects cloud. Therefore, it has no impact on the cloud flagging process in ORAC, and the application of the stereo-derived cloud mask as an input into the ORAC cloud masking routine is beyond the scope of this paper. The microphysical parameters assessed are cloud optical depth (COD), cloud effective radius $(\mathrm{RE})$, and cloud phase.

The CTH and phase assessments are made against collocated observations from the CALIOP lidar carried onboard the CALIPSO satellite. The assessment data set is obtained from observations within the geographical region of interest [latitudinal range: $50-85^{\circ} \mathrm{N}$; longitudinal range: $80^{\circ} \mathrm{W}-$ $5^{\circ} \mathrm{E}$ ] and its generation is explained in greater detail in Sect. 5.1. The limited, high latitude range of this data set is necessary to obtain collocations within suitably defined time limits.

Furthermore, the retrievals are evaluated separately over ice-covered and ice-free surfaces. As well as the limitations of the census algorithm over ice or snow surfaces, the ORAC retrievals are also expected to perform worse due to the difficulty in defining an accurate albedo and the increased difficulty of distinguishing clear-sky and cloud. In the analysis, it is assumed that all land areas are covered in ice (due to Greenland being the only substantial landmass in the geographical subset) and the AMSR-E sea-ice data set (Spreen et al., 2008) is used to enable differentiation between ice covered and ice free (effectively open water) water bodies.

\subsection{Comparison data set and method}

The CALIOP lidar has been making measurements of clouds and aerosols since 2006. The instrument is carried onboard the CALIPSO satellite, which is located in the NASA ATrain satellite constellation and therefore has an equatorial overpass time of approximately 1:30 p.m. and a 16-day orbital repeat cycle. The lidar has a ground footprint on the ellipsoid of $100 \mathrm{~m}$ and pulses every $333 \mathrm{~m}$ along track. It receives backscattered radiation in three channels, two at $532 \mathrm{~nm}$ with sensitivity to the backscattered intensity at orthogonal polarisations and one at $1064 \mathrm{~nm}$. The vertical resolution is between $30-60 \mathrm{~m}$ depending on the altitude of the cloud, with $30 \mathrm{~m}$ resolution achievable in the troposphere (Vaughan et al., 2009). If the uppermost cloud layer has an optical depth of less than 3 , then CALIOP is able to detect the presence of lower cloud layers (Vaughan et al., 2009). The cloud phase assignment is determined from the polarisation of the backscattered signal. With light backscattered from ice crystals depolarising in nature, whilst light backscattered from water clouds results in minimal depolarisation ( $\mathrm{Hu}$ et al., 2009). The CALIOP L1 data is processed into various L2 products, of which the $1 \mathrm{~km}$ cloud product, CAL_LID_L2_01 kmCLay-ValStage1-V3-01, is employed here for CTH and phase analysis due to its similar resolution to the AATSR instrument. The lower limit for cloud detection for this product is a backscattered signal of greater 
than $1 \times 10^{-3} \mathrm{~km}^{-1} \mathrm{sr}^{-1}$ (equivalent to an optical depth of 0.01 for cirrus clouds; McGill et al., 2007, Kahn et al., 2008; Vaughan et al., 2009). The AATSR data used in this comparison is the v2.0 Rutherford Appleton Laboratory (RAL) processed data product with calibration corrections provided by D. Smith at RAL (D. Smith, personal communication, 2014). There is an updated V2.1 processing available at RAL; however these data at present have not been evaluated for coregistration accuracy between the forward and nadir view, which is critical for accurate stereo CTH retrievals. A coregistration correction is applied here using the coefficients from Fisher and Muller (2013) that were derived using v2.0 RAL processed data, and are known to improve the coregistration accuracy to pixel level or better.

The calibrated and geometrically corrected AATSR $11 \mathrm{mi}-$ cron data are first processed using the census stereo algorithm, resulting in an geometric CTH estimate in metres for each valid image pixel. Each AATSR image pixel with a geometric CTH estimate is then assigned an uncertainty (in metres) using a look-up table derived from the approach described in Sect. 4. The ORAC retrieval ingests CTP a priori estimates and therefore conversion from CTH to CTP is required. The stereo $\mathrm{CTH}$ and the $\mathrm{CTH}$ uncertainty are converted to CTP using temporally interpolated geopotential height data from the ECMWF ERA Interim reanalyses (Simmons et al., 2007) gridcell that is collocated with the AATSR observation. It should be noted that this conversion process will introduce error into the a priori estimates; however in our analysis we make the assumption that the error introduced is of similar or lesser magnitude than the errors introduced by the camera model and wind effects. The output of the ORAC, ORAC+stereo, and census stereo processing is shown for a scene over the region of interest in Fig. 2.

For the period April to October 2008, a search for collocated AATSR-CALIPSO orbits within the study region was undertaken. This resulted in a total of 70 collocated AATSRCALIOP orbits split between the months of April, July, August, September and October (no collocations fulfilling the requirements were found for May or June). The CALIOP sampling over the ROI for the analysis is presented in Fig. 1. From these orbits, all cloud-containing $1 \mathrm{~km}$ CALIOP samples with a maximum of $40 \mathrm{~min}$ between overpasses were extracted for comparison against the AATSR retrievals. Here we make the assertion that, at least for CTH, that the impact of different sampling time on the analysis will be limited. This assertion is based on the assumption that CTH variation over scales of $200 \mathrm{~km}$ is well correlated (Jones, 1992), and that the cloud regime in a $200 \mathrm{~km}$ radius surrounding the collocation will not change within the 40 min between observations.

For each cloud-containing CALIOP sample we follow a similar approach to that used in Fisher et al. (2014) to extract the spatially and temporally collocated AATSR data. The process can be summarised as follows:

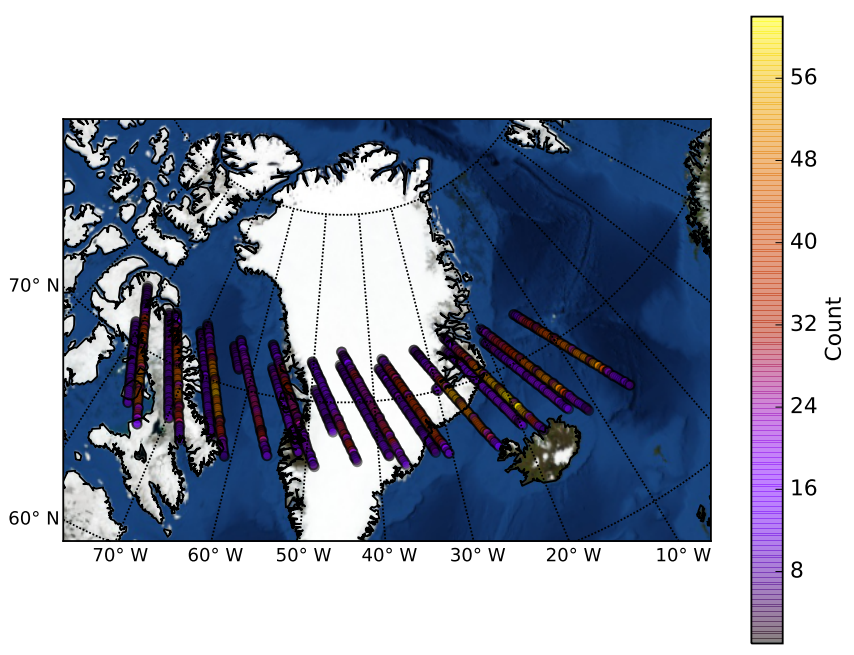

Figure 1. CALIOP sampling over the study region of interest.

- For each cloud-containing CALIOP $1 \mathrm{~km}$ sample, the associated latitude and longitude data are extracted and compared against the geographic grids from the temporally collocated AATSR product.

- The geographically collocated AATSR pixel to that of the cloud-containing CALIOP sample is determined by minimising the geographic distance using the Haversine formula. To be included in the analysis carried out here, the distance between the CALIOP sample and the closest AATSR pixel must be less than $5 \mathrm{~km}$.

- Once collocated, all a priori stereo heights within a 5by-5 pixel bounding box, centred on the geographically collocated AATSR pixel are considered. All of the a priori pixels within the bounding box are required to contain stereo-derived estimates for the collocated sample to be considered in the analysis. This requirement is in place to ensure that the effect of including stereo as a priori is not lost in the analyses in the following sections (a priori estimates are not available for all ORAC+stereo pixels, and in such instances ORAC and $\mathrm{ORAC}+$ stereo use the same a priori values).

- Assuming all pixels within the bounding box contain a priori stereo $\mathrm{CTH}$ estimates the absolute distance between the cloud-containing CALIOP sample's first cloud top layer (CTL) and the ORAC/ORAC+stereo retrieved CTH is computed. Note that the ORAC and ORAC+stereo CTP are converted into CTH using interpolated ERA-Interim data. The pixel index within the bounding box which minimises the absolute distance is used to extract the following ORAC/ORAC+stereo data: CTH, RE, COD, and phase. The following data from the CALIOP sample is also recorded: CTL, phase, and number of cloud layers. The underlying surface characteristics for the CALIOP sample are also 

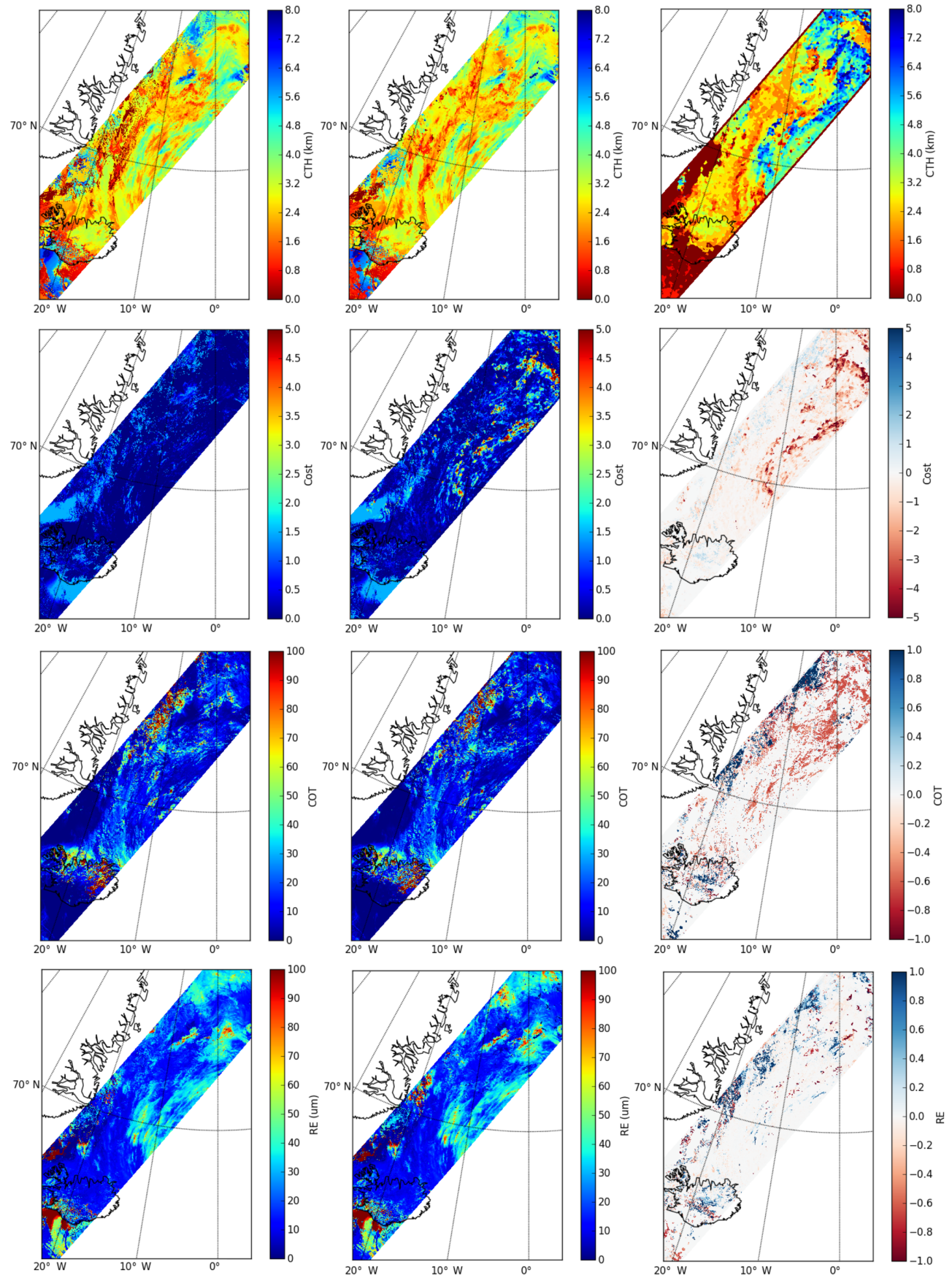

Figure 2. The top row of maps show CTH as retrieved by ORAC, ORAC+stereo and census stereo from left to right. The second row of maps shows the cost associated with each retrieved pixel, with the left plots the costs for ORAC, the central map plots the costs for ORAC+stereo, and the right map plots the difference between the costs. The third row shows the COT maps, with the same arrangement as the second row. The fourth row shows the RE maps with the same arrangement as the above two rows.

recorded, with any sample over land assumed to be icecovered, and the surface type over water being defined by the AMSR-E sea ice product.

This collocation process has been carried out for all CALIOP samples with AATSR pixels within a $5 \mathrm{~km}$ radius across the entire temporally collocated data set of 70 orbits, resulting in a potential total of 37767 collocated samples with at most 40 min between observations. 


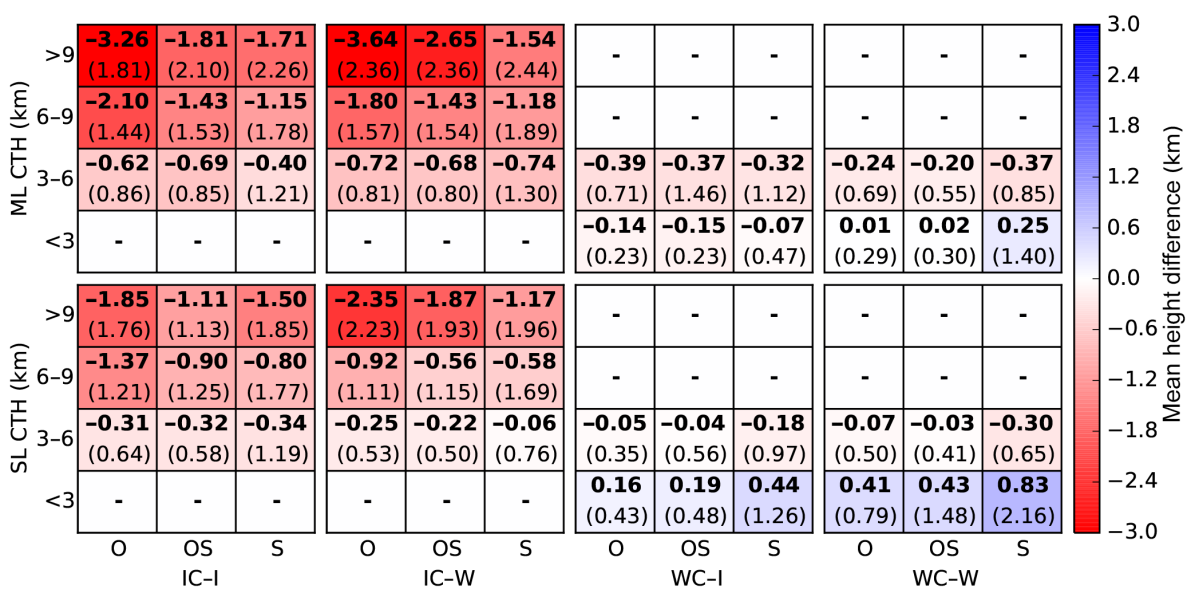

Figure 3. Mean CTH differences between the three algorithms and CALIOP where the ORAC and ORAC+stereo phases agree (standard deviation is included in the brackets). The codes employed in the table are as follows: O: ORAC; OS: ORAC+stereo; S: stereo; IC: ice cloud; WC: water cloud; I: ice-covered surface; W: water-covered surface; SL: single-layer cloud; and ML: multi-layer cloud.

\subsection{Analysis of cloud top height}

\subsubsection{CTH comparison overview}

The table presented in Fig. 3 provides an overview of the mean CTH differences between the collocated uppermost CALIOP CTL and ORAC, ORAC+stereo and census stereo CTH retrievals for all instances where the ORAC and ORAC+stereo phase are in agreement, resulting in 29687 collocated samples. The decision to restrict the analysis domain to only those samples with agreeing phase, whilst not strictly necessary for the CTH analysis, is to ensure a consistent sample in the microphysical and microphysical parameter analyses. Justification for this domain restriction in the microphysical analysis is provided in Sect. 5.3.3. The order of operation employed is subtraction of the CALIOP CTL from the AATSR CTH for each assessment (negative values equate to AATSR CTH being lower than CALIOP CTL; positive values equate to AATSR CTH being higher than CALIOP). In the analysis the clouds are binned into whether they are comprised of single or multi-layer regimes, with further binning based on CTL elevation, cloud phase and underlying surface type. The binning is determined using the CALIOP data for the cloud characteristics (CTL and phase of the uppermost cloud layer) and the AMSR-E data for the surface type. The CALIOP data is used to perform the data binning, as it is consistent, and provides all the parameters required for the binning process (e.g. the stereo retrieval does not provide an estimate of the cloud phase).

The first two sets of three columns of Fig. 3 show the ice cloud inter-comparisons, there are a number of key results. Firstly, ORAC is more negatively biased vs. CALIOP than either ORAC+stereo or census stereo for single and multilayer cloud systems over both surface types, and taking the means over all bins for each algorithm results in average bi- ases of $-1.6 \mathrm{~km}$ for ORAC, $-1.12 \mathrm{~km}$ for ORAC + stereo and $-0.93 \mathrm{~km}$ for stereo. Secondly, for all three algorithms, as the elevation of the ice cloud increases, so do the negative biases vs. CALIOP. This effect is stronger for ORAC than for ORAC+ + stereo: for all ice cloud combinations above $9 \mathrm{~km}$ the mean negative bias for ORAC is $-2.78 \mathrm{~km}$ vs. $-1.86 \mathrm{~km}$ for ORAC+stereo; for all ice cloud combinations between 6 and $9 \mathrm{~km}$ it is $-1.55 \mathrm{~km}$ vs. $-1.08 \mathrm{~km}$; and for all ice cloud combinations between 3 and $6 \mathrm{~km}$ it is $-0.48 \mathrm{~km}$ vs. $-0.48 \mathrm{~km}$. Thirdly, the negative bias is stronger for multi-layer clouds than for single-layer clouds for ORAC and ORAC+stereo. The number of cloud layers less affects census stereo, though an increased negative bias is also evident in multi-layer cloud systems. Lastly, in all ice cloud instances, the AATSR retrievals report negatives biases vs. CALIOP.

The second two sets of three columns show the intercomparisons for water clouds. The key results are, firstly, ORAC and ORAC+stereo both have very similar biases across all cloud regime and surface type combinations, and taking the means over all bins for each algorithm results in mean biases of $-0.04 \mathrm{~km}$ for ORAC and $-0.02 \mathrm{~km}$ for ORAC + stereo; secondly, for single-layer water clouds over both surface types and at elevations of $<3 \mathrm{~km}$ all three algorithms retrieve $\mathrm{CTH}$ with a positive bias vs. CALIOP. Thirdly, the census stereo algorithm experiences more retrieval noise when compared against CALIOP than either of the radiometric methods, particularly for water clouds at $<3 \mathrm{~km}$ with an average standard deviation taken over all surface types and single or multiple layers of $1.32 \mathrm{~km}$ for census stereo vs. $0.62 \mathrm{~km}$ for ORAC+stereo and $0.44 \mathrm{~km}$ for ORAC. This is also the case across the entire CTH analysis (ice and water clouds) with an average standard deviation across all bins of $1.45 \mathrm{~km}$ for census stereo, $1.07 \mathrm{~km}$ for ORAC+stereo and $1.02 \mathrm{~km}$ for ORAC. 

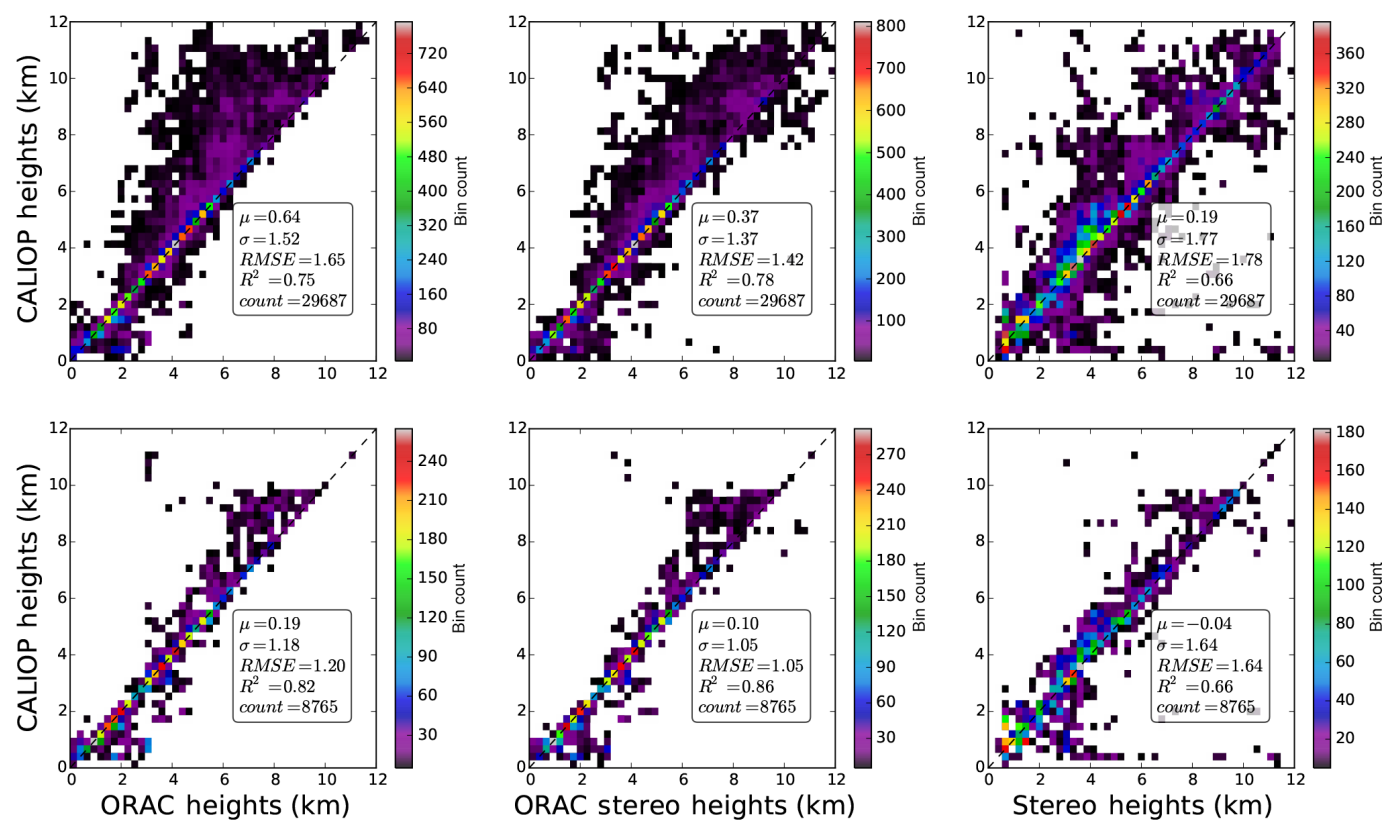

Figure 4. These plots contain the histogram analyses of CALIOP vs. ORAC, ORAC+stereo and census stereo. The upper row of histograms plots all available inter-comparison data where the phase retrieval between ORAC and ORAC+stereo agree. The bottom row of histograms plots the inter-comparison data following a screening process, where only those collocations with single-layer clouds (as determined by CALIOP) and surface ice concentrations of zero (as determined by AMSR-E) are considered. To be displayed the bin must contain more than 10 samples.

\subsubsection{Single-layer cloud}

From the statistical CTH overview shown in Fig. 3 and the joint histogram analyses presented in Fig. 4 it is apparent that high ice clouds deserve closer inspection to better understand the impact of employing census stereo data as an a priori on the retrieved CTHs. Another aspect, which is not clear from Fig. 3 (in part due to the CTH quantisation employed), but becomes apparent when looking at the profile plot shown in Fig. 5 and the joint histograms presented in Fig. 4, is the effect of incorporating census stereo a priori data on the accuracy of CTH retrievals within the atmospheric boundary layer.

The error-bar plot shown in Fig. 6 presents the median height differences between CALIOP and the ORAC, ORAC+stereo and census stereo CTH outputs across sets of $500 \mathrm{~m}$ intervals for all single-layer clouds over water where the retrieval phases agree, and with CTL altitudes determined by CALIOP to be between 6 and $12 \mathrm{~km}$. The analysis here focuses only on those multi-layer clouds with CTL altitudes as detected by CALIOP to be between 6 and $10.5 \mathrm{~km}$, as at altitudes above $10.5 \mathrm{~km}$, ORAC, ORAC+stereo and census stereo all show similar negatively biased behaviour, with median height differences of around $-1.5 \mathrm{~km}$. For all three retrievals, the heights are negatively biased vs. the CALIOP CTL for each height interval. The census stereo retrievals are the least negatively biased, and taking the average of the median differences for the height intervals between 6 and $10.5 \mathrm{~km}$ inclusive returns $-0.5 \pm 0.5 \mathrm{~km}$. The ORAC retrieval is the most negatively biased vs. CALIOP returning $-1.3 \pm 0.7 \mathrm{~km}$ when the median height differences are averaged. For ORAC+stereo there is a reduction in negative bias, although it still more negative than that of the stereo data, with an average median difference of $-0.9 \pm 0.7 \mathrm{~km}$. As the cloud altitude increases there is an increase in the negative bias of the ORAC and ORAC + stereo retrievals.

The error-bar plot in Fig. 7 presents the median height difference between CALIOP and the ORAC, ORAC+stereo and stereo CTH outputs across sets of $500 \mathrm{~m}$ height intervals for all single-layer clouds over water where the retrieval phases agree, and with CTL altitudes determined by CALIOP to be between 0 and $3 \mathrm{~km}$. For all clouds detected by CALIOP above $500 \mathrm{~m}$ altitude, there is good agreement between the data sets, with median height differences close to $0 \mathrm{~km}$. It should be noted that these small biases in the height assignment for low clouds are likely not representative of the performance globally; in polar regions there are few strong boundary layer inversions leading to the observed biases. For CTH retrievals with CALIOP observations with CTL altitudes in the $0-500 \mathrm{~m}$ range, the median differences for ORAC and ORAC+stereo show substantial divergence. The ORAC median difference is $1.33 \mathrm{~km}$, the ORAC+stereo is $0.23 \mathrm{~km}$, and census stereo is $0.43 \mathrm{~km}$. This indicates that the ORAC height assignments for clouds with altitudes of $<500 \mathrm{~m}$ are more often assigned with a positive bias than when the stereo data is used as a priori. This re- 


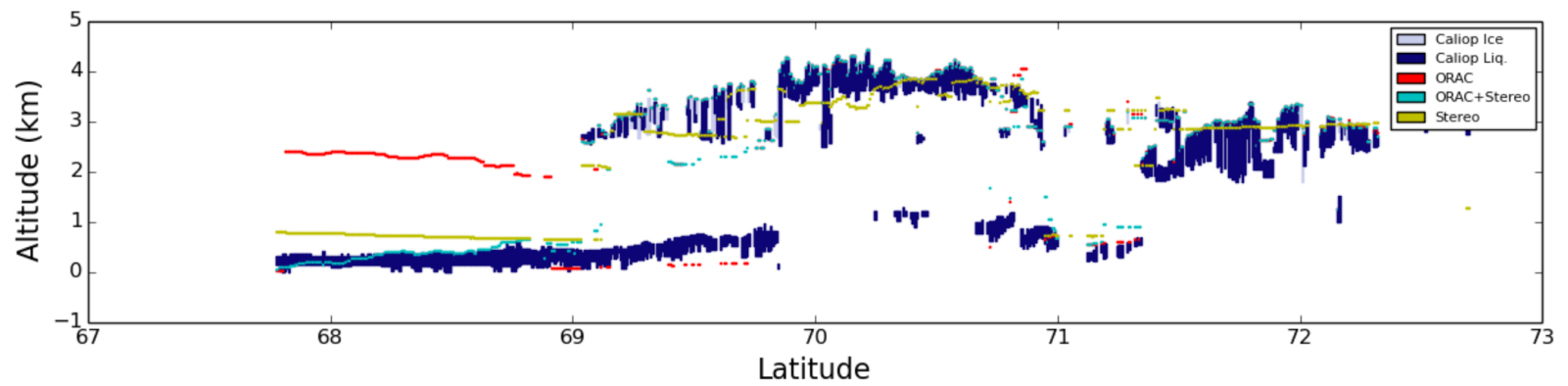

Figure 5. This profile plot show the $1 \mathrm{~km}$ CALIOP cloud profile for orbit with the time stamp 2008-07-05T13-02-15ZD. Over plot are the collocated CTH data from ORAC, ORAC+stereo, and census stereo. The key in the plot indicates the relationship between colour and feature type.

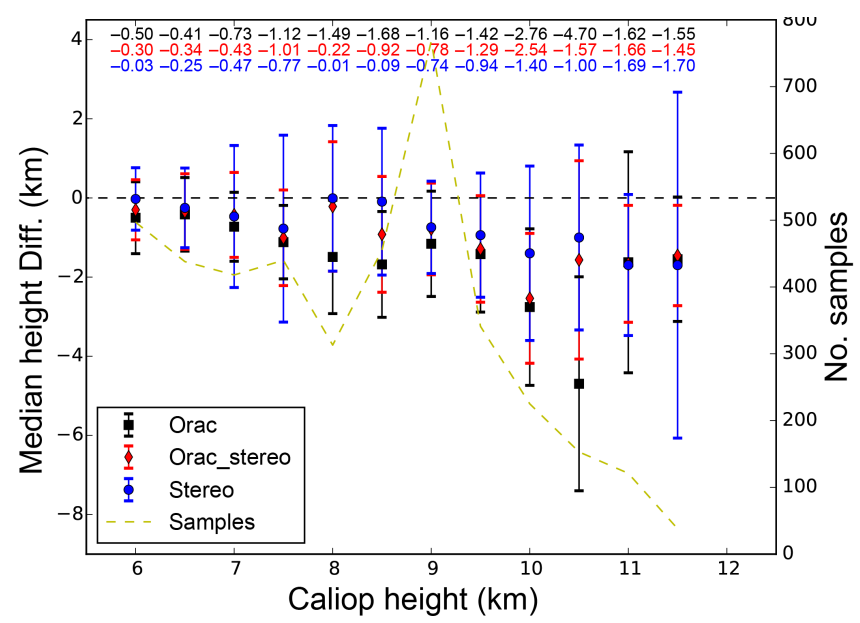

Figure 6. Error bar plot plotting the median height differences for single-layer ice clouds (over water where ORAC and ORAC+stereo phase agrees) at or above $6 \mathrm{~km}$ (as determined by CALIOP) for the three algorithms applied to AATSR and the elevation of the CALIOP CTL, as a function of the elevation of the CALIOP CTL at $500 \mathrm{~m}$ intervals (in this instance the median is derived from all collocated data contained within set given by the CALIOP CTL elevation indicated on the $x$ axis and all CALIOP CTL samples which are located within the following $500 \mathrm{~m}$, e.g. $6 \mathrm{~km} \leq \mathrm{CTL}<6.5 \mathrm{~km}$ ). The three statistics above each error bar are the median differences. The error-bar whiskers represent 1 standard deviation.

sult is also apparent in the screened joint histograms in Fig. 4 with the ORAC plot showing substantially higher bin counts than ORAC+stereo and stereo in the $2-4 \mathrm{~km} \mathrm{CTH}$ range for CALIOP CTLs in the $0-2 \mathrm{~km}$ range. The explanation here is that the ORAC cloud top height is often assigned too high particularly where there is a boundary layer inversion and more than one temperature/height solution is possible. The stereo CTH provides an additional useful constraint that results in correct height retrieval more often.

Generalising over all heights, cloud types and surface types we can say that, while the ORAC+stereo bias it still larger than the stereo bias, the correlation has increased and

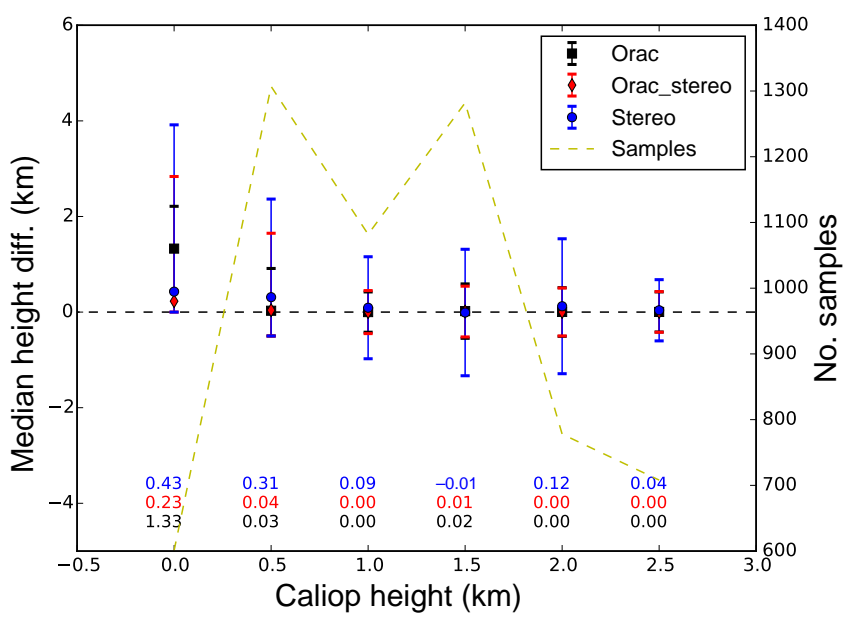

Figure 7. Error bar plot plotting the median height differences for single-layer water clouds (over water where ORAC and ORAC+stereo phase agrees) below $3 \mathrm{~km}$ (as determined by CALIOP) for the three algorithms applied to AATSR and the elevation of the CALIOP CTL, as a function of the elevation of the CALIOP CTL at $500 \mathrm{~m}$ intervals (in this instance the median is derived from all collocated data contained within set given by the CALIOP CTL elevation indicated on the $x$ axis and all CALIOP CTL samples which are located within the following $500 \mathrm{~m}$, e.g. $0 \mathrm{~km} \leq \mathrm{CTL}<0.5 \mathrm{~km}$ ). The three statistics below each error bar are the median differences. The error-bar whiskers represent 1 standard deviation.

the standard deviation has decreased, significantly indicating that the "noise" on the stereo retrieval is greatly reduced and the fine scale structure of the cloud top retained.

\subsubsection{Multi-layer cloud}

The error-bar plot shown in Fig. 8 presents the median height difference between CALIOP and the ORAC, ORAC+stereo and stereo CTH outputs across sets of $500 \mathrm{~m}$ intervals for all multi-layer clouds over water where the retrieval phases agree, and with the uppermost CTL altitudes determined by CALIOP to be between 6 and $12 \mathrm{~km}$. The analysis here, how- 


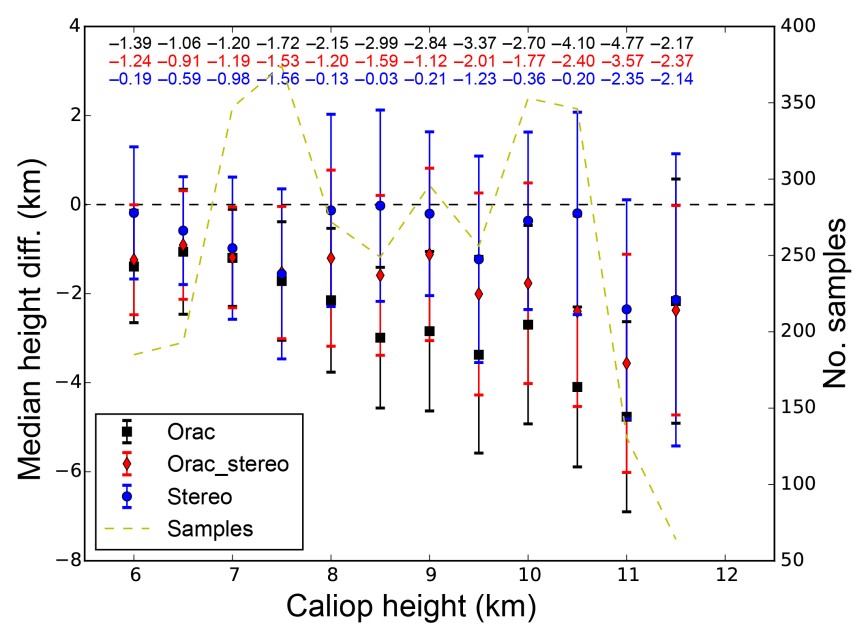

Figure 8. Error bar plot plotting the median height differences for multi-layer ice clouds (over water where ORAC and ORAC+stereo phase agrees) at or above $6 \mathrm{~km}$ (as determined by the uppermost CALIOP CTL elevation) for the three algorithms applied to AATSR and the elevation of the uppermost CALIOP CTL, as a function of the elevation of the uppermost CALIOP CTL at $500 \mathrm{~m}$ intervals (in this instance the median is derived from all collocated data contained within set given by the uppermost CALIOP CTL elevation indicated on the $x$ axis and all uppermost CALIOP CTL samples which are located within the following $500 \mathrm{~m}$, e.g. $6 \mathrm{~km} \leq \mathrm{CTL}<6.5 \mathrm{~km}$ ). The three statistics above each error bar are the median differences. The error-bar whiskers represent 1 standard deviation.

ever, focuses only on those multi-layer clouds with CTL altitudes as detected by CALIOP to be between 6 and $10.5 \mathrm{~km}$. As with the single-layer high cloud analysis, at altitudes above $10.5 \mathrm{~km}$ ORAC, ORAC+stereo and census stereo all show median height differences vs. CALIOP of typically $<-2 \mathrm{~km}$. The retrievals are again negatively biased vs. CALIOP, with similar behaviour in the case of single-layer clouds and with ORAC exhibiting the most negative bias and stereo the least. The average median difference for ORAC is larger than with single-layer clouds at $-2.2 \pm 0.9 \mathrm{~km}$ as is the ORAC+stereo at $-1.4 \pm 0.4 \mathrm{~km}$. The stereo retrieval performs similarly to the single-layer cloud assessment, with an average median height difference vs. CALIOP of $-0.6 \pm$ $0.6 \mathrm{~km}$. As the cloud altitude increases, in general, there is an increase in the negative bias of ORAC and the other retrievals perform with similar behaviour.

\subsection{Cloud microphysical property analyses}

Traditional cloud retrievals tend to perform height and microphysical property retrievals separately; however, the problem with this technique is that it can be difficult to balance the LW and SW radiative effects of the clouds (Ham et al., 2009). While the visible and near-infrared channels are mostly sensitive to the effective radius and optical depth, the infrared channels provide the most information about cloud top height with all channels contributing to a lesser or greater degree to all cloud properties. Hence it is important to evaluate the effect of cloud top height a priori adjustment on the microphysical parameters within the ORAC retrieval scheme. In Sect. 5.3.1 an overview of the differences between the ORAC and the ORAC+stereo COT and RE retrievals is provided, in Sect. 5.3.2 we look at the effect of the a priori on the cloud phase retrieval and provide an inter-comparison against CALIOP to assess these changes, and in Sect. 5.3.3 we examine the effect of the inclusion of the $\mathrm{CTH}$ a priori on the retrieved COT and RE parameters both in the presence and absence of phase differences.

\subsubsection{COT and RE comparison overview}

The table presented in Fig. 9 provides an overview of the mean COT, RE and CTH differences between the ORAC and ORAC+stereo retrievals for all instances where the ORAC and ORAC+stereo phase are in agreement, giving a total of 29687 samples used to generate the table. The order of operation employed is subtraction of the ORAC+stereo measurement from the ORAC measurement for each assessment (negative values equate to the $\mathrm{ORAC}+$ stereo retrieval being on average larger than ORAC retrieval; positive values equate to the ORAC+stereo retrieval being on average smaller than the ORAC retrieval). As with the CTH analysis presented in Fig. 3 the parameters are binned into whether they are observations from single or multi-layer cloud regimes, with further binning based on CTL elevation, cloud phase and underlying surface type with the binning defined by CALIOP and AMSR-E.

The first two sets of three columns of Fig. 9 show the COT and RE inter-comparisons for ice clouds. There are a number of key results. Firstly, the least consistency between the ORAC and the ORAC+stereo COT retrievals are those over ice-covered surfaces. The standard deviations of the COT differences range from 15.9 to 38.1 under such conditions. For retrievals over water, there is improved consistency and the standard deviations of the COT differences range from 1.0 to 4.9. Secondly, the mean COT difference magnitudes between the ORAC and ORAC+stereo retrievals tend to be less than 5 over all ice cloud combinations, with ORAC on average retrieving larger COT values than $\mathrm{ORAC}+$ stereo. The only exception is for single-layer ice clouds between 3 and $6 \mathrm{~km}$ where the inclusion of the a priori in ORAC+stereo leads to COT retrievals that are on average 11.9 larger than those from ORAC. Thirdly, the RE retrievals have similar mean difference magnitudes $(<2.2$ microns) and standard deviations ( $<8.3$ microns) over both surface types, except in the case of single-layer ice clouds over ice. In such conditions the uncertainty is far greater with a standard deviation of 12.4 microns for ice clouds between $6-9 \mathrm{~km}$ and $16.3 \mathrm{mi}-$ crons for ice clouds between $3-6 \mathrm{~km}$.

The second two sets of three columns of Fig. 9 present the COT and RE inter-comparisons for water clouds. There are 


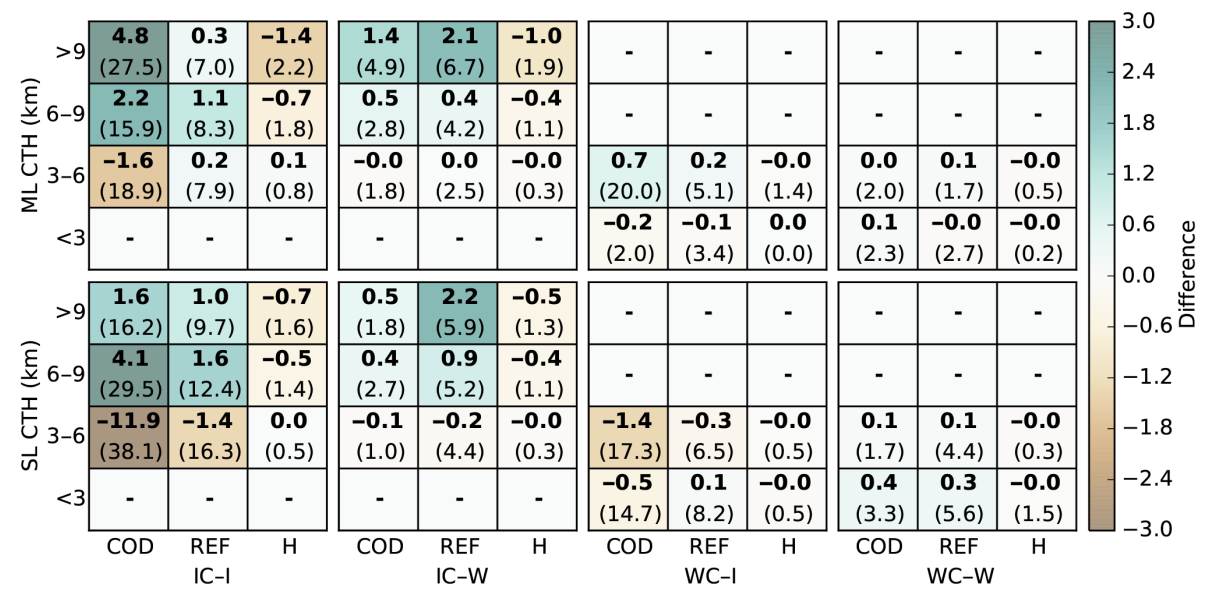

Figure 9. Mean microphysical differences between the ORAC and ORAC+stereo retrievals for various cloud and surface combinations where the ORAC and ORAC+stereo phases agree (the cloud height bins are defined by CALIOP, the surface bins by AMSR-E sea-ice product). See macrophysical table in Fig. 3 for codes to interpret table.

a number of keys results. Firstly, the least consistency between the ORAC and the ORAC+stereo COT retrievals are again over ice-covered surfaces. The standard deviations of the COT differences range from 2 to 20 under such conditions. For retrievals over water there is improved consistency and the standard deviations of the COT differences range from 1.7 to 3.3. Secondly, the mean COT difference magnitude does not exceed 1.4 in any of the water cloud comparisons. Thirdly, the RE analysis show similar mean differences (magnitudes $<0.3$ microns) and standard deviations ( $<5.6$ microns) over both surface types, except in the case of single-layer water clouds over ice. In such cases the uncertainty is increased with a standard deviation of 6.5 microns for water clouds between $3-6 \mathrm{~km}$ and 8.2 microns for water $<3 \mathrm{~km}$.

\subsubsection{Phase Comparison vs. CALIOP}

Figures 10 and 11 present joint histograms of the COT and RE retrievals for single-layer clouds over water from ORAC and ORAC+stereo for when the phases of the algorithms agree and when they disagree, respectively. What is apparent is that phase changes, caused by the inclusion of the $\mathrm{CTH}$ a priori, are the main driver behind the observed differences in the COT and RE retrievals. This is further analysed in Table 1 where the ORAC and ORAC+stereo phase retrievals are compared against the CALIOP retrieved phase (where CALIOP phase flags of 1 or 3 are considered to be ice, and phase flags of 2 are considered to be water). Of the 9941 single-layer cloud retrievals over water, 1176 exhibit a change of phase between the ORAC and ORAC+stereo retrievals. When phase changes occur, the phase assigned by ORAC+stereo appears to typically be incorrect, at least in comparison to the CALIOP retrieved phase: phase agreements of $12.6 \%$ at $3 \mathrm{~km}, 16.5 \%$ at $3-6 \mathrm{~km}, 11.7 \%$ at 6
$9 \mathrm{~km}$ and $43.7 \%$ at $>9 \mathrm{~km}$ are found for ORAC+stereo vs. CALIOP, compared to phase agreements of $87.4 \%$ at $<3 \mathrm{~km}$, $83.5 \%$ at $3-6 \mathrm{~km}, 88.3 \%$ at $6-9 \mathrm{~km}$ and $56.3 \%$ at $>9 \mathrm{~km}$ for ORAC vs. CALIOP. When ORAC and ORAC+stereo retrieve the same phase, agreements of $81.9 \%$ for clouds at $<3 \mathrm{~km}, 64.9 \%$ for clouds between $3-6 \mathrm{~km}, 97.9 \%$ for clouds between $6-9 \mathrm{~km}$ and $71.1 \%$ for clouds at $>9 \mathrm{~km}$ vs. CALIOP are found.

When phase differences occur between the retrievals they are associated with larger retrieval uncertainty as indicated by larger retrieval costs. For ORAC the mean costs for singlelayer clouds over water ranges from 6.22 to 52.35 when there is phase disagreement vs. 5.07 to 9.89 when the phases agree. Similarly for ORAC+stereo the mean costs for single-layer clouds over water ranges from 37.65 to 313.16 when there is phase disagreement vs. 12.59 to 19.11 when the phases agree. This provides an indication that when the phases disagree retrieval conditions are more challenging, and that the ORAC algorithm, with or without a priori, retrieves moderate to poor quality forward model fits.

\subsubsection{COT and RE joint histogram analysis}

In Fig. 10 a joint histogram analysis of COT retrieved by ORAC and ORAC+stereo is presented for single-layer clouds over ice-free surfaces. The top row of plots $(\mathrm{a}-\mathrm{c})$ present all the data; here however, the focus is on the analysis of where the phase of the retrievals agree, shown in the bottom row of plots $(\mathrm{d}-\mathrm{f})$. Ensuring phase agreement allows analysis of the effect of the inclusion of the a priori CTH on the microphysical parameter (COT or RE) rather than any effect on the microphysical parameter caused by a change in phase. The total number of samples where phase agrees is 8765. The key result from the COT intercomparison with phase agreement is that the inclusion of the $\mathrm{CTH}$ a priori 

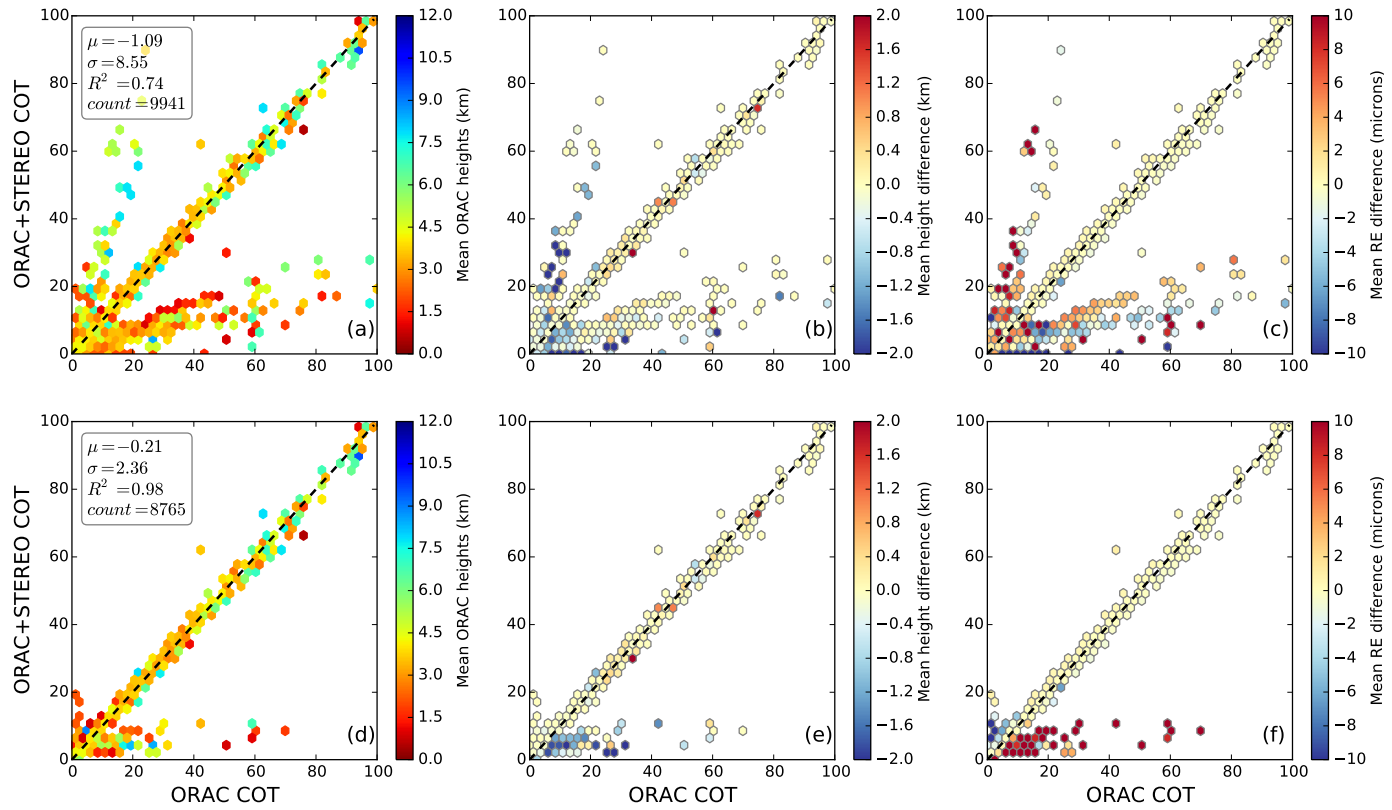

Figure 10. Joint histograms of COT as retrieved by ORAC and by ORAC+stereo. Plots (a-c) show the samples for all single-layer clouds over water (number of layers determined by CALIOP and open water determined by AMSR-E). Plots (d-f) show the subset of the sample where the ORAC and ORAC+stereo phases are in agreement.
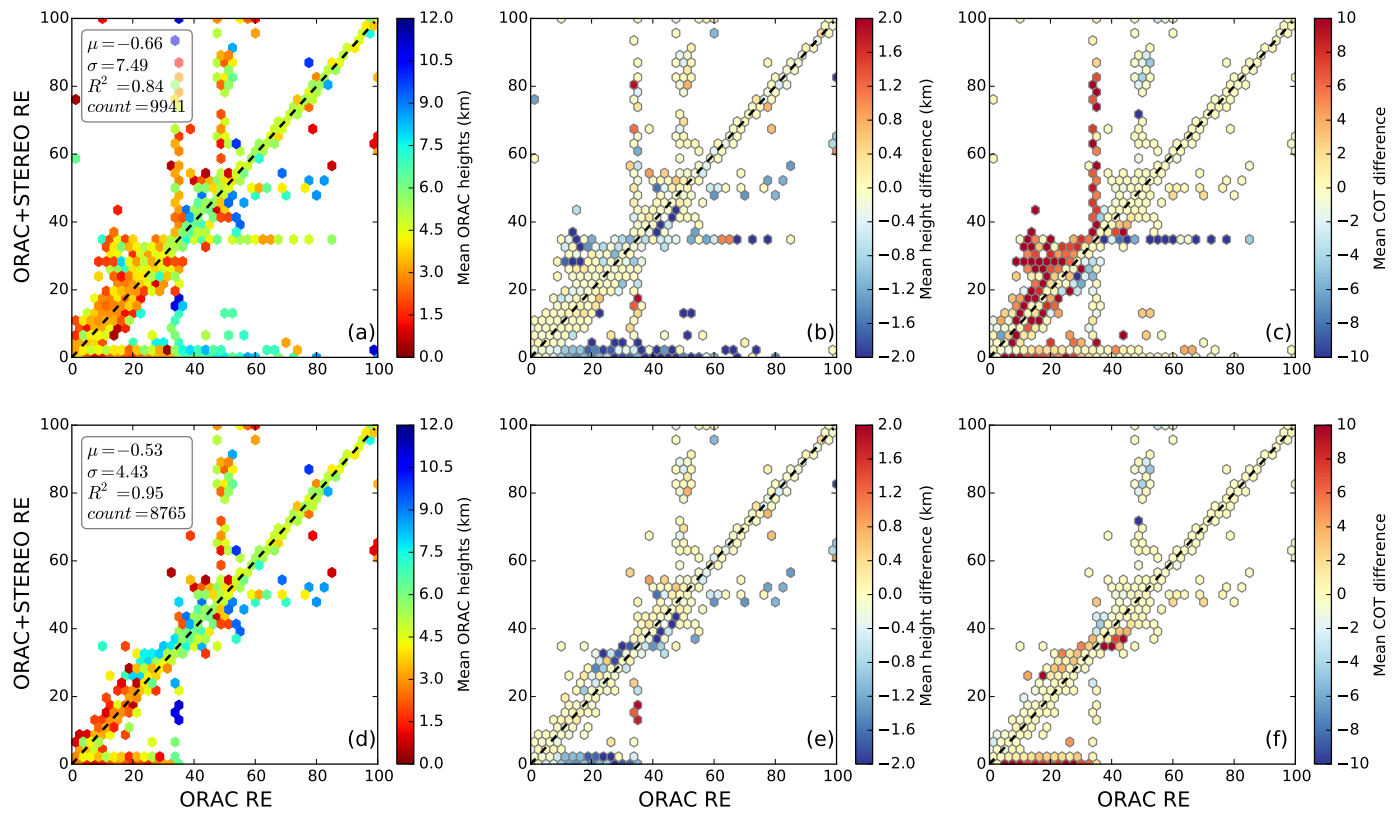

Figure 11. Joint histograms of RE as retrieved by ORAC and by ORAC+stereo. Plots (a-c) show the samples for all single-layer clouds over water (number of layers determined by CALIOP and open water determined by AMSR-E). Plots (d-f) show the subset of the sample where the ORAC and ORAC+stereo phases are in agreement.

leads to only small changes in the retrieved COT, with a mean difference of $-0.21( \pm 2.36)$. Furthermore excellent agreement is demonstrated between the retrievals with a coefficient of determination of 0.98 .
In Fig. 11 a joint histogram analysis of the RE as retrieved by ORAC and ORAC+stereo is presented for singlelayer clouds over ice-free surfaces. Again we focus only on analysing those cases where the retrieval phases are in agreement (plots $\mathrm{d}-\mathrm{f}$ ). The mean difference between the ORAC 
Table 1. Comparison of ORAC and ORAC+stereo phase retrievals counts against collocated CALIOP samples for single-layer clouds over water (determined by CALIOP and AMSR-E, respectively). In the "phase agrees" rows, both ORAC and ORAC +stereo retrieve the same phase. In the "phase disagrees" rows ORAC and ORAC+stereo retrieve opposite phases. For example taking the entries for 0-3 km for phase disagrees: ORAC retrieves 90 samples with ice phase and ORAC+stereo retrieves 90 samples with water phase; ORAC retrieves 432 samples with water phase and ORAC+stereo 432 samples with ice phase.

\begin{tabular}{lrrrrrrr}
\hline & $\begin{array}{r}\text { TOTAL } \\
\text { Samples }\end{array}$ & $\begin{array}{r}\text { ORAC } \\
\text { Ice phase }\end{array}$ & $\begin{array}{r}\text { ORAC } \\
\text { Water phase }\end{array}$ & $\begin{array}{r}\text { CAL } \\
\text { Ice phase }\end{array}$ & $\begin{array}{r}\text { CAL } \\
\text { Water phase }\end{array}$ & $\begin{array}{r}\text { ORAC } \\
\text { Mean Cost }\end{array}$ & $\begin{array}{r}\text { ORAC-ST } \\
\text { Mean Cost }\end{array}$ \\
\hline Phase agrees & & & & & & & \\
\hline $0-3 \mathrm{~km}$ & 3477 & 817 & 2660 & 188 & 3263 & 9.24 & 17.25 \\
$3-6 \mathrm{~km}$ & 3186 & 1774 & 1412 & 657 & 2502 & 9.89 & 14.68 \\
$6-9 \mathrm{~km}$ & 1404 & 1210 & 194 & 1236 & 164 & 5.37 & 19.11 \\
$>9 \mathrm{~km}$ & 698 & 496 & 202 & 698 & 0 & 5.07 & 12.59 \\
\hline Phase disagrees & & & & & & & \\
\hline $0-3 \mathrm{~km}$ & 522 & 90 & 432 & 24 & 487 & 52.35 & 235.55 \\
$3-6 \mathrm{~km}$ & 436 & 129 & 307 & 57 & 373 & 36.96 & 37.65 \\
$6-9 \mathrm{~km}$ & 154 & 119 & 35 & 136 & 17 & 11.79 & 184.58 \\
$>9 \mathrm{~km}$ & 64 & 36 & 28 & 64 & 0 & 6.22 & 313.16 \\
\hline
\end{tabular}

and ORAC+stereo RE retrievals with phase agreement is $-0.53( \pm 4.43)$ microns. The coefficient of determination is 0.95. Assessing the ice cloud RE retrievals only, a mean difference of $0.2( \pm 4.05)$ microns and a coefficient of determination of 0.96 are obtained from 4297 observations. In the case of water cloud RE, a mean difference of -1.23 $( \pm 4.65)$ microns and a coefficient of determination of 0.52 are obtained from 4468 observations.

The reduced agreement between the RE retrievals for water clouds is caused two distinct regimes that are apparent in Fig. 11 for retrievals at less than 40 microns. One group is aligned to the one-to-one line showing good agreement between the retrievals. The other is aligned along the $x$ axis showing that ORAC+stereo retrieval is underestimating the RE compared with the ORAC retrieval. Analysing the retrievals costs of these groups: the group with good agreement has a mean ORAC retrieval cost of 7.2 and a mean ORAC+stereo retrieval cost of 11.5 ; the group with poor agreement has a mean ORAC retrieval cost of 8.5 and a mean ORAC+stereo retrieval cost of 103.7. The cause of the high ORAC+stereo retrieval costs in the group with poor agreement is poor a priori estimates from the census stereo algorithm. The mean retrieved heights from the group with poor agreement are the following: $8.09 \mathrm{~km}$ for census stereo, $4.75 \mathrm{~km}$ for ORAC+stereo, and $3.57 \mathrm{~km}$ for ORAC. This is in comparison to mean heights from the group with good agreement: $2.65 \mathrm{~km}$ for census stereo, $2.75 \mathrm{~km}$ for ORAC+stereo, and $2.78 \mathrm{~km}$ for ORAC. Excluding the group with poor a priori estimates from census stereo a mean RE difference between the retrievals of $0.02( \pm 0.75)$, and a coefficient of determination of 0.98 are obtained from 4109 water cloud samples. The set of poor a priori values for water clouds is also the cause of the apparent underestimation of COD by ORAC+stereo for clouds with ORAC retrieved COD of $<20$ (Fig. 10, plots d-f).

\section{Discussion}

\subsection{Impact on cloud top height retrieval}

The analyses in Sect. 5.2 demonstrate that, for a number of different cloud conditions, the inclusion of stereo a priori data provides improvements in the ORAC CTH retrieval when compared to CALIOP. In the case of low clouds, such as stratocumulus, it is well known that radiative based retrieval algorithms, such as ORAC, typically exhibit CTH/CTP (cloud top pressure) retrievals which are biased too low or too high depending on whether the temperature profile is searched for a temperature match to the TOA brightness temperatures from the surface up, or the top of the profiles down, respectively. In the case of ORAC the temperature profile is searched from the top down and consequently the cloud top height is often assigned too high. These biases are caused by the fact that low-level stratocumulus clouds often occur in the presence of temperature inversions, and the atmospheric temperature profiles employed to convert between the retrieved temperature and CTP often do not effectively represent either the strength or the position of the inversion. A clear example of this is in the CALIOP profile plot in Fig. 5, where the water cloud feature detected by CALIOP at approximately $500 \mathrm{~m}$ between the latitudes of 68 and $69^{\circ}$ latitude is poorly captured by the ORAC retrieval, which instead assigns CTHs at around $2.5 \mathrm{~km}$ (likely the top of the temperature inversion). The census stereo approach relies on the geometry of the instrument to assign height and therefore is completely independent of any tem- 
perature profile assumptions. In the case of boundary layer clouds, this leads to a significant reduction in bias in the retrieved CTHs as shown in the analysis in Sect. 5, and the profile plot in Fig. 5. The drawback of the stereo approach, aside from the fact that it only provides $\mathrm{CTH}$, is a tendency to smooth the disparity field losing fine detail information on CTH. This effect is apparent in the following: the profile plot in Fig. 5 where the stereo heights entirely miss the fine scale detail of the cloud profile as determined by CALIOP; the census stereo output in the stereo CTH retrieval shown in Fig. 2, where the stereo algorithm misses much of the fine scale detail captured by ORAC; and the joint histogram in Fig. 4, particularly for CALIOP CTLs at altitudes between 2 and $6 \mathrm{~km}$, where there is a small but significant underestimation of the CTH by the census stereo algorithm, which is caused by the inability of the stereo algorithm to capture the finer scale CTH changes. Another potential drawback of the census stereo algorithm when applied to AATSR thermal channel is that it has a tendency to be noisy for low, particularly boundary layer, clouds, as demonstrated by the very large standard deviations (up to $4 \mathrm{~km}$ ) in Fig. 7. This is also caused by the smoothing effect of the stereo algorithm, where stereo height retrievals from clouds above the boundary layer clouds "bleed" across the discontinuity leading to erroneous height assignments (high bias) for the boundary layer cloud. The drawbacks of the stereo algorithm, however, are somewhat mitigated (and the benefits retained), when employed as a priori in the ORAC retrieval. When combined, the accuracy of the ORAC+stereo retrieval is better for the height assignment of low-level boundary layer clouds than census stereo applied to the thermal channel due to increased sensitivity to fine detail cloud structure, and substantially better than ORAC due to the improved a priori estimates providing the necessary constraint to overcome the inversion layer degeneracy.

Cirrus and other high altitude type cloud formations, if they have low optical depth, present a challenging cloud form to assign CTH to for both radiometric and geometric type algorithms. In the presence of a low optical depth cloud, the cloud top temperature retrieved by radiative based algorithms such as ORAC corresponds to a cloud top height typically 1 optical depth into the cloud, which for many clouds may not correspond with the true $\mathrm{CTH}$ but rather a significant low bias, particularly for optically thin clouds with large vertical extent. For geometric type algorithms, the retrieved CTH is associated with the location within the cloud where the optical depth is sufficient to provide suitable image texture for reliable stereo image matching; this may also be some way below the true cloud top. Note that the stereo algorithm uses the dual view capability of ATSR while the ORAC retrieval uses only the nadir view. Since the forward view has twice the path length though a cloud, the penetration depth is approximately half of the nadir view. This is consistent with the results presented in the joint histograms in Fig. 4, which demonstrate for clouds above $8 \mathrm{~km}$ that the census stereo ob- servations tend to have reduced low biases (approx. half) than ORAC when compared to the CTL altitude as determined by CALIOP. This observation is made more concrete in Fig. 6 and the statistical analyses provided in Sect. 5.2, where the census stereo CTH retrievals, at least for clouds less than $11 \mathrm{~km}$ in altitude, typically have a much reduced low bias than the ORAC retrievals. For clouds above $11 \mathrm{~km}$ in the inter-comparison regions, it is likely that the optical depth is too low for any of the algorithms to perform effectively. When the stereo retrievals are incorporated into the ORAC retrieval as a priori, the low bias is still present, but reduced. Further reductions in the ORAC+stereo bias could potentially be achieved by reducing the uncertainties on the stereo a priori inputs for high clouds and by using the dual view in the ORAC cloud retrieval, both of which will be examined in the future.

Similar findings to those of single-layer high ice clouds are presented for the case of multi-layer clouds where the uppermost layer is above $6 \mathrm{~km}$ (and therefore ice). This is to be expected, as in the instances of optically thin cloud, rather than having the surface contributing to the observed radiance, it is instead the underlying cloud feature. However, the low biases in the ORAC retrievals for multi-layer clouds, as shown in Fig. 8, are generally larger than for the single-layer cloud case. This is likely due to the assumptions of the single-layer cloud model employed by ORAC and the fact that in case of multi-layer clouds, the retrieved cloud top height is related to the effective radiance of the two layers, which will be an intermediate height. As with single-layer clouds when the stereo retrievals are incorporated into the ORAC retrieval as a priori the low biases compared to the CALIOP CTL are generally reduced, but not to the same extent as stereo alone, due to the fact that the most radiometrically consistent cloudtop height remains below the height of the upper layer cloud layer if a single cloud layer is assumed. The stereo retrieval performs similarly irrespective of the number of cloud layers, and this is a feature of the geometric approach.

\subsection{Impact on cloud optical properties}

The analysis in Sect. 5.3 demonstrates two situations where the inclusion of the CTH a priori has a large impact on the retrieved microphysical parameters. The first is where the inclusion of the a priori leads to a change in cloud phase. A change in cloud phase has a strong effect on the retrieved COD and RE parameters as water and ice cloud microphysics differ substantially. Changes in cloud phase occurred in $\sim 10 \%$ of the collocated samples analysed for single cloud over water and, in comparison against CALIOP, the change in phase caused by the inclusion of the a priori is typically incorrect. However, the samples with phase changes between the retrievals are also associated with average solution costs that indicate moderate to poor/very poor quality fits for both ORAC (excluding ice clouds $>9 \mathrm{~km}$, where the mean cost is $\sim 6$ ) and ORAC+stereo. The higher mean so- 
lution costs indicate that when retrievals settle on different phases the observed conditions are not well approximated by either forward model. Causes of this poor approximation can include: multi-layer clouds (that may have been missed by CALIOP due it saturating at three optical depths), the presence of mixed phase cloud and high aerosol loading, or regions where the auxiliary data or a priori data are not appropriately defined (Sayer et al., 2011). In this instance though, an inappropriately defined CTH a priori is likely not the cause as the high costs are also present in the ORAC retrieval where it is not applied.

The second situation where the inclusion of the a priori has a significant impact is for certain water cloud retrievals. The observed discrepancies in the retrieved microphysical parameters are caused by inaccurate a priori estimates of CTH from the census stereo algorithm. The poor estimates occur where the water cloud intersects with other cloud features at higher elevations. Near the point of intersection, due to stereo algorithm smoothing effects (Zabih and Woodfill, 1994), the census stereo retrieved CTH relates to the overlying cloud feature, not the underlying water cloud, resulting in inaccurate a priori values. The ORAC + stereo retrieval is constrained against these CTH a priori values, and the degree of the constraint is dependent on the provided a priori error (Poulsen et al., 2012). In our analysis the census stereo a priori was found to be wildly inaccurate at intersections between water clouds and overlying clouds $(\sim 8 \mathrm{~km}$ mean CTH vs. $\sim 3 \mathrm{~km}$ mean CTH retrieved by ORAC), in such instances the assumed error on the a priori is unsuitable, and does not provide a sensible constraint for the retrieval. In order to reproduce the observed top of atmosphere brightness temperatures the algorithm must modify other, unconstrained parameters. The inadequacy of the CTH a priori values and the provided error constraints are therefore compensated for in the COD and RE parameters, which are unconstrained in the ORAC retrieval (Poulsen et al., 2012). This results in the observed differences between the ORAC and the ORAC + stereo COD and $\mathrm{RE}$ retrievals for water clouds located in proximity to clouds at increased elevations. In such instances, the ORAC + stereo $\mathrm{COD}$ and RE retrievals are incorrect and methods for detecting when the stereo-derived a priori is inappropriate so that effective a priori estimates and errors can be applied will be investigated in future studies.

Outside of these two situations the impact of the a priori on the retrieved cloud microphysical parameters is limited. Poor agreement between the ORAC and ORAC +stereo microphysical parameters is observed in retrievals over ice (and to a far lesser degree, multi-layer cloud systems); however this is expected due to the known behaviours and limitations of the ORAC algorithm (Sayer et al., 2011). In retrieval situations where ORAC is known to perform optimally (singlelayer clouds over ice-free water bodies in this instance) the mean differences between the algorithms are small. The inclusion of the a priori and the associated increase in $\mathrm{CTH}$ (as with high ice clouds) leads to a slight reduction in the retrieved COT and RE that is dependent on the change in $\mathrm{CTH}$. The largest observed magnitude changes are for singlelayer ice clouds over open water at elevations of above $9 \mathrm{~km}$ (which are most strongly affected by the inclusion of the a priori) with mean RE differences of $2.2( \pm 5.9)$ and mean COD differences of $0.5( \pm 1.8)$.

\section{Conclusions}

For the first time, a synergistic application of radiometric and geometric cloud retrieval approaches has been carried out. This synergy was achieved using the AATSR instrument by employing census stereo-derived CTHs as a priori inputs into the ORAC retrieval. The stereo-derived a priori data act as constraints on the ORAC retrieval, constraining the range of the potential solutions of the optimal estimation algorithm. This technique makes optimal use of the design of the ATSR instrument: the stereo retrieval uses the ATSR dual view to achieve accurate cloud top height assignment, while ORAC uses well calibrated radiometric information to retrieve fine scale height information, cloud optical depth and effective radius. The techniques are combined using the optimal estimation framework, which provides a mathematically rigorous way of accounting for the uncertainty on the a priori information.

The effect of the inclusion of the stereo a priori data has been evaluated for both cloud macro- and micro-physical properties. In terms of macrophysics an extensive intercomparison was made against collocated CALIOP lidar observations for various cloud and surface types. The analyses result in a number of interesting findings. The inclusion of stereo-derived a priori leads to a substantial improvement of the retrieval in the presence of boundary layer clouds reducing the median height difference vs. CALIOP for clouds at altitudes of less than $500 \mathrm{~m}$ from 1.33 to $0.23 \mathrm{~km}$, indicating a substantial reduction in high bias. This is particularly important as changes in boundary layer clouds, particularly marine boundary layer clouds, represent a particularly poorly constrained response to climate change in climate (Zelinka et al., 2013; Sherwood et al., 2014).

In the case of high single- and multi-layer clouds a reduction in low bias is found, with the average median difference for ORAC being $-1.3 \mathrm{~km}$ and then $-0.9 \mathrm{~km}$ with the inclusion of stereo a priori, in the case of single-layer clouds, $-2.2 \mathrm{~km}$ and then $-1.4 \mathrm{~km}$ for multi-layer clouds. However, the stereo retrieved CTH from the 11 micron channel show far reduced low biases, with average median height differences of $0.4 \mathrm{~km}$ irrespective of cloud type. A future way to exploit the stereo information further would be to include the stereo information as a priori information in a multi-layer model, such a model is currently being developed by various groups (Watts et al., 2011).

In terms of cloud microphysics, the inclusion of the stereo a priori usually has a limited impact on the retrieved param- 
eters. Two particular cases where the inclusion of the a priori had a large effect on the retrieved cloud microphysics were established: firstly, where the inclusion of the a priori leads to a change of phase; and secondly, where the a priori is assigned too high, leading to erroneous COD and RE retrievals. The phase changes caused by the inclusion of the a priori are connected to challenging retrieval situations where the ORAC retrieval performed poorly regardless of the a priori (as indicated by the retrieval costs). The overly high a priori CTH assignments are caused by stereo smoothing errors; positively these situations were identified with a high cost. The removal or reduction of such smoothing artefacts is a key requirement for effective inclusion of the census stereo $\mathrm{CTH}$ a priori at the intersection of clouds at differing elevations. Particularly when there is a large height difference between the cloud layers, such as boundary layer clouds intersecting with cirrus clouds. Outside of these cases the largest difference in microphysical retrievals in optimal retrieval conditions (single-layer cloud over open water, in this instance) were observed for single-layer ice clouds over open water at elevations of above $9 \mathrm{~km}$ (which are most strongly affected by the inclusion of the a priori) with mean RE differences of $2.2( \pm 5.9)$ and mean COD differences of $0.5( \pm 1.8)$.

To summarise, the inclusion of stereo a priori data into the ORAC retrieval appears to improve performance in the presence of challenging cloud situations, particularly for boundary layer clouds and high-level ice clouds in terms of CTH assignment, and leads to small adjustments in the retrieved microphysical parameters in most cases. More of the information in the stereo retrieval could be taken advantage of consistently when used in conjunction with a multi-layer model. It is worth noting that the technique demonstrated here is not limited to the ATSR series of instruments and cloud retrievals, but could be applied to ATSR retrievals of aerosol and aerosol layer height, particularly for desert dust storms, fire plumes and volcanic ash clouds, and also other multi view instruments such as MISR and the soon-to-belaunched Sea and Land Surface Temperature (SLSTR). The technique also has potential to be applied to multiple geostationary satellite instruments with overlapping fields of view.

Acknowledgements. Many thanks to Phil Watts for discussions on stereo data independence. This work has been funded by NCEO and by NERC under PhD studentship number NER/S/C/2006/14369 and uses the ESA CCI cloud algorithm code.

Edited by: A. Kokhanovsky

\section{References}

Allan, R. P.: Combining satellite data and models to estimate cloud radiative effect at the surface and in the atmosphere, Meteorol. Appl., 18, 324-333, 2011.
Andrews, T., Gregory, J. M., Webb, M. J., and Taylor, K. E.: Forcing, feedbacks and climate sensitivity in CMIP5 coupled atmosphere-ocean climate models, Geophys. Res. Lett., 39, L09712, doi:10.1029/2012GL051607, 2012.

Ardanuy, P. E., Stowe, L. L., Gruber, A., and Weiss, M.: Shortwave, longwave, and net cloud-radiative forcing as determined from Nimbus 7 observations, J. Geophys. Res.-Atmos., 96, 1853718549, 1991.

Baum, B. A. and Wielicki, B. A.: Cirrus cloud retrieval using infrared sounding data - multilevel cloud errors, J. Appl. Meteorol., 33, 107-117, 1994.

Baran, A. J., Shcherbakov, V. N., Baker, B. A., Gayet, J. F., and Lawson, R. P.: On the scattering phase function of nonsymmetric ice crystals, Q. J. Roy. Meteor. Soc., 131, 2609-2616, 2005.

Cess, R. D.: Climate change: An appraisal of atmospheric feedback mechanisms employing zonal climatology, J. Atmos. Sci., 33, 1831-1843, 1976.

Cess, R. D., Potter, G. L., Blanchet, J. P., Boer, G. J., Ghan, S. J., Kiehl, J. T., Le Treut, H., Li, Z.-X., Liang, X.-Z., Mitchell, J. F. B., Morcrette, J.-J., Randall, D. A., Riches, M. R., Roeckner, E., Schlese, U., Slingo, A., Taylor, K. E., Washington, W. M., Wetherald, R. T., and Yagai, I.: Interpretation of cloud-climate feedback as produced by 14 atmospheric general circulation models, Science, 245, 513-516, doi:10.1126/science.245.4917.513, 1989.

Cess, R. D., Potter, G. L., Blanchet, J. P., Boer, G. J., Del Genio, A. D., Déqué, M., Dymnikov, V., Galin, V., Gates, W. L., Ghan, S. J., Kiehl, J. T., Lacis, A. A., Le Treut, H., Li, Z.-X., Liang, X.-Z., McAvaney, B. J., Meleshko, V. P., Mitchell, J. F. B., Morcrette, J.-J., Randall, D. A., Rikus, L., Roeckner, E., Royer, J. F., Schlese, U., Sheinin, D. A., Slingo, A., Sokolov, A. P., Taylor, K. E., Washington, W. M., Wetherald, R. T., Yagai, I., and Zhang, M.-H.: Intercomparison and interpretation of climate feedback processes in 19 atmospheric general circulation models, J. Geophys. Res.-Atmos., 95, 16601-16615, 1990.

Cess, R. D., Zhang, M. H., Ingram, W. J., Potter, G. L., Alekseev, V., Barker, H. W., Cohen-Solal, E., Colman, R. A., Dazlich, D. A., Del Genio, A. D., Dix, M. R., Dymnikov, V., Esch, M., Fowler, L. D., Fraser, J. R., Galin, V., Gates, W. L., Hack, J. J., Kiehl, J. T., Le Treut, H., Lo, K. K.-W., McAvaney, B. J., Meleshko, V. P., Morcrette, J.-J., Randall, D. A., Roeckner, E., Royer, J.-F., Schlesinger, M. E., Sporyshev, P. V., Timbal, B., Volodin, E. M., Taylor, K. E., Wang, W., and Wetherald, R. T.: Cloud feedback in atmospheric general circulation models: an update, J. Geophys. Res.-Atmos., 101, 12791-12794, 1996.

Colman, R.: A comparison of climate feedbacks in general circulation models, Clim. Dynam., 20, 865-873, 2003.

Danielson, J. J. and Gesch, D. B.: Global multi-resolution terrain elevation data 2010 (GMTED2010), US Geological Survey OpenFile Report, 1073, 26, 2011.

Denis, M. A., Muller, J. P., and Mannstein, H.: ATSR-2 camera models for the automated stereo photogrammetric retrieval of cloud-top heights - initial assessments, Int. J. Remote Sens., 28, 1939-1955, 2007.

Fisher, D. and Muller, J. P.: Global warping coefficients for improving ATSR co-registration, Remote Sensing Letters, 4, 151-160, 2013.

Fisher, D., Muller, J. P., and Yershov, V. N.: Automated stereo retrieval of smoke plume injection heights and retrieval of 
smoke plume masks from AATSR and their assessment with CALIPSO and MISR, IEEE T. Geosci. Remote, 52, 1249-1258, doi:10.1109/TGRS.2013.2249073, 2014.

Garay, M. J., de Szoeke, S. P., and Moroney, C. M.: Comparison of marine stratocumulus cloud top heights in the southeastern Pacific retrieved from satellites with coincident shipbased observations, J. Geophys. Res.-Atmos., 113, D18204, doi:10.1029/2008JD009975, 2008.

Ham, S.-H., Sohn, B.-J., Yang, P., and Baum, B.: Assessment of the quality of MODIS Cloud products from radiance simulations, $\mathrm{J}$. Appl. Meterol., 48, 1591-1612, 2009.

Heidinger, A. K., Pavolonis, M. J., Holz, R. E., Baum, B. A., and Berthier, S.: Using CALIPSO to explore the sensitivity to cirrus height in the infrared observations from NPOESS/VIIRS and GOES-R/ABI, J. Geophys. Res.-Atmos., 115, D00H20, doi:10.1029/2009JD012152, 2010.

Hirschmuller, H. and Scharstein, D.: Evaluation of stereo matching costs on images with radiometric differences, IEEE T. Pattern Anal., 31, 1582-1599, 2009.

Hu, Y., Winker, D., Vaughan, M., Lin, B., Omar, A., Trepte, C., Flittner, D., Yang, P., Nasiri, S. L., Baum, B., and Holz, R.: CALIPSO/CALIOP cloud phase discrimination algorithm, J. Atmos. Ocean. Tech., 26, 2293-2309, 2009.

Istomina, L. G., von Hoyningen-Huene, W., Kokhanovsky, A. A., and Burrows, J. P.: The detection of cloud-free snow-covered areas using AATSR measurements, Atmos. Meas. Tech., 3, 10051017, doi:10.5194/amt-3-1005-2010, 2010.

Jones, P. A.: Cloud-cover distributions and correlations, J. Appl. Meteorol., 31, 732-741, 1992.

Kahn, R. A., Chen, Y., Nelson, D. L., Leung, F. Y., Li, Q., Diner, D. J., and Logan, J. A.: Wildfire smoke injection heights: Two perspectives from space, Geophys. Res. Lett., 35, L04809, doi:10.1029/2007GL032165, 2008.

Kiehl, J. T., Hack, J. J., and Briegleb, B. P.: The simulated Earth radiation budget of the National Center for Atmospheric Research community climate model CCM2 and comparisons with the Earth Radiation Budget Experiment (ERBE), J. Geophys. Res.-Atmos., 99, 20815-20827, 1994.

Kiehl, J. T. and Trenberth, K. E.: Earth's annual global mean energy budget, B. Am. Meteorol. Soc., 78, 197-208, 1997.

Llewellyn-Jones, D., Edwards, M., Mutlow, C., Birks, A., Barton, I., and Tait, H.: AATSR: Global-change and surface-temperature measurements from Envisat, Esa Bull-Eur. Space, 11-21, 2001.

Lorenz, D.: Stereoscopic imaging from polar orbit and synthetic stereo imaging, Adv. Space Res., 2, 133-142, 1985.

Marchand, R., Ackerman, T., Smyth, M., and Rossow, W. B.: A review of cloud top height and optical depth histograms from MISR, ISCCP, and MODIS, J. Geophys. Res.-Atmos., 115, D16206, doi:10.1029/2009JD013422, 2010.

McGill, M. J., Vaughan, M. A., Trepte, C. R., Hart, W. D., Hlavka, D. L., Winker, D. M., and Kuehn, R.: Airborne validation of spatial properties measured by the CALIPSO lidar, J. Geophys. Res.-Atmos., 112, D20201, doi:10.1029/2007JD008768, 2007.

Menzel, W. P., Smith, W. L., and Stewart, T. R.: Improved cloud motion wind vector and altitude assignment using VAS, J. Clim. Appl. Meteorol., 22, 377-384, 1983.

Menzel, W. P., Frey, R. A., Zhang, H., Wylie, D. P., Moeller, C. C., Holz, R. E., Maddux, B., Baum, B. A., Strabala, K. I., and Gum- ley, L. E.: MODIS global cloud-top pressure and amount estimation: algorithm description and results, J. Appl. Meteorol. Clim., 47, 1175-1198, 2008.

Moroney, C., Davies, R., and Muller, J. P.: Operational retrieval of cloud-top heights using MISR data, IEEE T. Geosci. Remote, 40, 1532-1540, 2002.

Mueller, K., Moroney, C., Jovanovic, V., Garay, M. J., Muller, J. P., Di Girolamo, L., and Davies, R.: MISR Level 2 cloud product algorithm theoretical basis, JPL Tech. Doc. D-73327, Jet Propul. Lab., Calif. Inst. of Technol., Pasadena., 2013.

Muller, J. P., Mandanayake, A., Moroney, C., Davies, R., Diner, D. J., and Paradise, S.: MISR stereoscopic image matchers: techniques and results, IEEE T. Geosci. Remote, 40, 15471559, 2002.

Muller, J. P., Denis, M. A., Dundas, R. D., Mitchell, K. L., Naud, C., and Mannstein, H.: Stereo cloud-top heights and cloud fraction retrieval from ATSR-2, Int. J. Remote Sens., 28, 1921-1938, 2007.

Mutlow, C. T., Murray, M. J., Bailey, P., and Birks, A.: ATSR-1/2 user guide issue 1, ESA user Guide, 2391, 1999.

Nakajima, T., Tanaka, M., and King, M. D.: Determination of the optical thickness and effective particle radius of clouds from reflected solar radiation measurements, Part I: Theory, J. Atmos. Sci., 47, 187-193, 1990.

Ohring, G., Wielicki, B., Spencer, R., Emery, B., and Datla, R.: Satellite instrument calibration for measuring global climate change, B. Am. Meteorol. Soc., 86, 1303, doi:10.1175/BAMS86-9-1303, 2005.

Poulsen, C. A., Siddans, R., Thomas, G. E., Sayer, A. M., Grainger, R. G., Campmany, E., Dean, S. M., Arnold, C., and Watts, P. D.: Cloud retrievals from satellite data using optimal estimation: evaluation and application to ATSR, Atmos. Meas. Tech., 5, 1889-1910, doi:10.5194/amt-5-1889-2012, 2012.

Prata, A. J. and Turner, P. J.: Cloud-top height determination using ATSR data, Remote Sens. Environ., 59, 1-13, 1997.

Ramanathan, V. L. R. D., Cess, R. D., Harrison, E. F., Minnis, P., Barkstrom, B. R., Ahmad, E., and Hartmann, D.: Cloud-radiative forcing and climate: results from the Earth radiation budget experiment, Science, 243, 57-63, 1989.

Rodgers, C. D.: Inverse methods for atmospheric sounding: theory and practice/series on atmospheric, Oceanic and Planetary Physics, Vol. 2, World Scientific Publishing, Singapore, 2000.

Rossow, W. B. and Garder, L. C.: Cloud detection using satellite measurements of infrared and visible radiances for ISCCP, J. Climate, 6, 2341-2369, 1993.

Rossow, W. B., Zhang, Y., and Wang, J.: A statistical model of cloud vertical structure based on reconciling cloud layer amounts inferred from satellites and radiosonde humidity profiles, J. Climate, 18, 3587-3605, 2005.

Sayer, A. M., Thomas, G. E., and Grainger, R. G.: A sea surface reflectance model for (A)ATSR, and application to aerosol retrievals, Atmos. Meas. Tech., 3, 813-838, doi:10.5194/amt-3813-2010, 2010.

Sayer, A. M., Poulsen, C. A., Arnold, C., Campmany, E., Dean, S., Ewen, G. B. L., Grainger, R. G., Lawrence, B. N., Siddans, R., Thomas, G. E., and Watts, P. D.: Global retrieval of ATSR cloud parameters and evaluation (GRAPE): dataset assessment, Atmos. Chem. Phys., 11, 3913-3936, doi:10.5194/acp-11-39132011, 2011. 
Scharstein, D. and Szeliski, R.: A taxonomy and evaluation of dense two-frame stereo correspondence algorithms, International journal of computer vision, 47, 7-42, 2002.

Seemann, S. W., Borbas, E. E., Knuteson, R. O., Stephenson, G. R., and Huang, H.-L.: Development of a global infrared land surface emissivity database for application to clear sky sounding retrievals from multi-spectral satellite radiance measurements, J. Appl. Meteorol. Clim., 47, 108-123, 2008.

Seiz, G.: Ground-and satellite-based multi-view determination of 3D cloud geometry, Doctoral dissertation, $\mathrm{PhD}$ thesis, Institute of Geodesy and Photogrammetry, IGP Mitteilungen, ETH Zurich, Switzerland, 2003.

Sherwood, S. C., Bony, S., and Dufresne, J. L.: Spread in model climate sensitivity traced to atmospheric convective mixing, Nature, 505, 37-42, 2014.

Shin, D. and Pollard, J. K.: Cloud height determination from satellite stereo images, in: Image Processing for Remote Sensing, IEE Colloquium on (4-1), IET, doi:doi: 10.1049/ic:19960158, 1996.

Simmons, A., Uppala, S., Dee, D., and Kobayashi, S.: ERA-Interim: New ECMWF reanalysis products from 1989 onwards, ECMWF newsletter, 110, 25-35, 2007.

Smith, D., Mutlow, C., Delderfield, J., Watkins, B., and Mason, G.: ATSR infrared radiometric calibration and in-orbit performance, Remote Sens. Environ., 116, 4-16, 2012.

Soden, B. J. and Held, I. M.: An assessment of climate feedbacks in coupled ocean-atmosphere models, J. Climate, 19, 3354-3360, 2006.

Soden, B. J., Held, I. M., Colman, R., Shell, K. M., Kiehl, J. T., and Shields, C. A.: Quantifying climate feedbacks using radiative kernels, J. Climate, 21, 3504-3520, 2008.

Spreen, G., Kaleschke, L., and Heygster, G.: Sea ice remote sensing using AMSR-E $89 \mathrm{GHz}$ channels, J. Geophys. Res.-Oceans, 113, C02S03, doi:10.1029/2005JC003384, 2008.

Stamnes, K., Tsay, S. C., Wiscombe, W., and Jayaweera, K.: Numerically stable algorithm for discrete-ordinate-method radiative transfer in multiple scattering and emitting layered media, Appl. Optics, 27, 2502-2509, 1988.

Stengel, M., Mieruch, S., Jerg, M., Karlsson, K.-G., Scheirer, R., Maddux, B., Meirink, J. F., Poulsen, C., Siddans, R., Walther, A., and Hollmann, R.: The clouds climate change initiative: assessment of state-of-the-art cloud property retrieval schemes applied to AVHRR heritage measurements, Remote Sens. Environ., 162, 363-379, doi:10.1016/j.rse.2013.10.035, 2013.

Stephens, G. L.: Cloud feedbacks in the climate system: a critical review, J. Climate, 18, 237-273, 2005.

Stocker, T. F., Qin, D., Plattner, G. K., Tignor, M., Allen, S. K., Boschung, J., Nauels, A., Xia, Y., Bex, V., and Midgley, P. M.: Climate change 2013: The Physical Science Basis, Contribution of Working Group I to the Fifth Assessment Report of the Intergovernmental Panel on Climate Change, Cambridge, UK, and New York, Cambridge University Press, 2013.
Stubenrauch, C. J., Rossow, W. B., Kinne, S., Ackerman, S., Cesana, G., Chepfer, H., Di Girolamo, L., Getzewich, B., Guignard, A., Heidinger, A., Maddux, B. C., Menzel, W. P., Minnis, P., Pearl, C., Platnick, S., Poulsen, C., Riedi, J., Sun-Mack, S., Walther, A., Winker, D., Zeng, S., and Zhao, G.: Assessment of global cloud datasets from satellites: project and database initiated by the GEWEX radiation panel, B. Am. Meteorol. Soc., 94, 1031-1049, 2013.

Vaughan, M. A., Powell, K. A., Winker, D. M., Hostetler, C. A., Kuehn, R. E., Hunt, W. H., Getzewich, B. J., Young, S. A., Liu, Z., and McGill, M. J.: Fully automated detection of cloud and aerosol layers in the CALIPSO lidar measurements, J. Atmos. Ocean. Tech., 26, 2034-2050, 2009.

Watts, P. D., Mutlow, C. T., Baran, A. J., and Zavody, A. M.: Study on cloud properties derived from Meteosat Second Generation Observations, Eumetsat Report, 2393-2403, 1998.

Watts, P. D., Bennartz, R., and Fell, F.: Retrieval of twolayer cloud properties from multispectral observations using optimal estimation, J. Geophys. Res.-Atmos., 116, D16203, doi:10.1029/2011JD015883, 2011.

Webb, M. J., Senior, C. A., Sexton, D. M. H., Ingram, W. J., Williams, K. D., Ringer, M. A., McAvaney, B. J., Colman, R., Soden, B. J., Gudgel, R., Knutson, T., Emori, S., Ogura, T., Tsushima, Y., Andronova, N., Li, B., Musat, I., Bony, S., and Taylor, K. E.: On the contribution of local feedback mechanisms to the range of climate sensitivity in two GCM ensembles, Clim. Dynam., 27, 17-38, 2006.

Wetherald, R. T. and Manabe, S.: Cloud feedback processes in a general circulation model, J. Atmos. Sci., 45, 1397-1416, 1988.

Wielicki, B. A., Barkstrom, B. R., Harrison, E. F., Lee III, R. B., Louis Smith, G., and Cooper, J. E.: Clouds and the Earth's radiant energy system (CERES): an earth observing system experiment, B. Am. Meteorol. Soc., 77, 853-868, 1996.

Winker, D. M., Vaughan, M. A., Omar, A., Hu, Y., Powell, K. A., Liu, Z., Hunt, W. H., and Young, S. A.: Overview of the CALIPSO mission and CALIOP data processing algorithms, J. Atmos. Ocean. Tech., 26, 2310-2323, 2009.

Zabih, R. and Woodfill, J.: Non-parametric local transforms for computing visual correspondence, in: Computer Vision ECCV'94, Springer Berlin, Heidelberg, 151-158, 1994.

Zelinka, M. D., Klein, S. A., Taylor, K. E., Andrews, T., Webb, M. J., Gregory, J. M., and Forster, P. M.: Contributions of different cloud types to feedbacks and rapid adjustments in CMIP5*, J. Climate, 26, 5007-5027, 2013. 